\title{
CATALISAdORES HETEROGÊNEOS PARA A PRODUÇÃo DE MONOÉSTERES GRAXOS (BIODIESEL)
}

\author{
Claudiney Soares Cordeiro, Fabiano Rosa da Silva, Fernando Wypych e Luiz Pereira Ramos* \\ Departamento de Química, Universidade Federal do Paraná, CP 19081, 81531-980 Curitiba - PR, Brasil
}

Recebido em 16/6/09; aceito em 29/9/10; publicado na web em 7/1/11

\begin{abstract}
HETEROGENEOUS CATALYSTS FOR BIODIESEL PRODUCTION. The recent increase in the world biodiesel demand, along with the need to reduce costs while improving the environmental sustainability of the entire biodiesel production chain, have led to the search for heterogeneous catalysts that would be efficient and highly amenable to recycling. Many classes of materials have been tested for these purposes. Among these are zeolites, ion-exchange resins, inorganic oxides, guanidines, metal complexes, layered compounds and ionic liquids. This review article describes the structure, properties, synthesis and performance of compounds that are catalytic active in both esterification and transesterification reactions.
\end{abstract}

Keywords: heterogeneous catalysts; alcoholysis; esterification.

\section{INTRODUÇÃO}

O uso de combustíveis fósseis é a principal causa do aumento da concentração de gases do efeito estufa na atmosfera. Segundo a Organização das Nações Unidas (ONU), a temperatura média da Terra aumentará entre 1,8 e $4^{\circ} \mathrm{C}$ até o ano de 2100 e isto deverá acelerar o derretimento das geleiras, elevar o nível dos oceanos e provocar intensos furacões. O balanço hídrico do planeta também deverá ser alterado, paralelamente ao índice pluviométrico de várias regiões. ${ }^{1}$

O biodiesel pode ser produzido pela transesterificação, também conhecida como alcoólise, de óleos vegetais e/ou gorduras animais, ou pela esterificação de ácidos graxos livres, mediante a utilização de um catalisador ácido, básico ou enzimático, que pode ser homogêneo ou heterogêneo. Trata-se de um biocombustível que possui grande adaptabilidade à tecnologia atual dos motores do ciclo-diesel, configurando-se como uma alternativa técnica capaz de atender de imediato a toda a frota já existente e movida a diesel de petróleo. O biodiesel também apresenta várias vantagens ambientais em relação ao petrodiesel, como baixos níveis de emissão de monóxido de carbono e material particulado durante a combustão, a não liberação de compostos de enxofre na atmosfera, melhores propriedades combustíveis como o número de cetano e menores emissões dos principais gases do efeito estufa, pois o gás carbônico produzido na sua combustão é quase que totalmente fixado durante o cultivo das oleaginosas. ${ }^{2,3}$

Industrialmente, o biodiesel ainda é em grande parte produzido por catálise alcalina em meio homogêneo, utilizando alcóxidos metálicos como catalisadores e variando-se o tipo de óleo vegetal, de acordo com a região. Entretanto, para que este processo seja tecnicamente viável, o óleo deve conter baixo teor de ácidos graxos livres para evitar o consumo do catalisador alcalino e assim reduzir o rendimento do processo de alcoólise. Outro requisito importante é que o material graxo possua baixo teor de umidade. Isto porque a água desloca o equilíbrio químico em favor da hidrólise do alcóxido, produzindo o álcool correspondente e o hidróxido do metal utilizado como contra-íon do alcóxido. Além disso, a presença de água pode induzir a hidrólise dos monoésteres produzidos, aumentando assim a possibilidade da formação de emulsões e de uma consequente redução no rendimento do processo. ${ }^{4}$

*e-mail: luiz.ramos@ufpr.br
Quando bases como o NaOH ou KOH são utilizadas na alcoólise, o íon alcóxido é produzido in situ para então promover o ataque nucleofílico à carbonila do acilglicerol. ${ }^{4}$ Embora este processo proporcione altos rendimentos em monoésteres alquílicos, sob condições ideais de reação, as etapas subsequentes de purificação são bastante onerosas em função dos monoésteres e, principalmente, da glicerina obtida como coproduto no processo, apresentarem contaminação com sais, acilglicerois, sabões, entre outros. Tal fato exige a realização de várias operações unitárias de purificação, que aumentam o investimento de capital e, portanto, encarecem o processo.

Os ácidos de Brönsted-Lowry também podem ser utilizados como catalisadores homogêneos para produção do biodiesel, porém, a cinética da alcoólise é lenta e requer que a reação seja realizada próxima da temperatura de ebulição do álcool utilizado como agente de transesterificação. Canacki e Gerpen ${ }^{5}$ obtiveram rendimentos de 98\% na metanólise do óleo de soja, com a reação sendo realizada com razão molar álcool:óleo (RM) de 30:1, 3\% de $\mathrm{H}_{2} \mathrm{SO}_{4}$ a $60{ }^{\circ} \mathrm{C}$ por $48 \mathrm{~h}$.

A catálise ácida também pode ser uma estratégia interessante para a neutralização de materiais lipídicos que apresentem elevada acidez. Desta forma, após a esterificação dos ácidos graxos livres presentes nestas matérias graxas, os triacilglicerois remanescentes podem ser transesterificados via catálise alcalina convencional. A transesterificação e esterificação simultâneas em meio ácido também são possíveis, porém, conforme já discutido, a cinética de transesterificação ácida é consideravelmente mais lenta em relação à catálise alcalina tradicional. ${ }^{5}$

Uma alternativa para a produção de biodiesel é a hidroesterificação, a qual consiste na hidrólise dos triacilglicerois, seguida da esterificação dos ácidos graxos livres gerados. A vantagem deste processo reside na possibilidade da utilização de matérias-primas de menor valor agregado, independentemente de sua acidez e umidade. Isso evita problemas de contaminação do biodiesel com resíduos de glicerol livre ou total (mono, di e triacilglicerois), gerando-se um produto de alta qualidade e uma glicerina com elevado grau de pureza. No entanto, a dificuldade na recuperação da glicerina é a grande desvantagem deste processo, já que esta sai muito diluída da etapa de hidrólise. ${ }^{6}$

A síntese do biodiesel também pode ser realizada por catálise heterogênea. Tal estratégia oferece vantagens técnicas e ambientais 
em relação à catálise homogênea, pois facilita a purificação dos monoésteres alquilícos, permite a reciclagem do catalisador sólido ao longo de sua vida útil e minimiza a geração de efluentes. Além disso, facilita consideravelmente a recuperação e a purificação da glicerina. Vários sólidos têm sido propostos como catalisadores em potencial para a síntese do biodiesel. O desempenho destes materiais como catalisadores está naturalmente relacionado com a natureza dos sítios ácidos ou básicos encontrados nestes materiais. ${ }^{7}$

A atividade catalítica de sólidos que possuam sítios básicos de Brönsted-Lowry está relacionada a fenômenos de interação entre o álcool usado como agente de transesterificação e a superfície do sólido catalítico. Desta forma, os alcóxidos são gerados na superfície através da troca de cátions como o sódio, em uma zeólita NaX, com o hidrogênio do álcool empregado na reação (Figura 1a). No caso de sólidos básicos de Brönsted-Lowry, que possuam em sua superfície um grupamento amônio quaternário $\left(\mathrm{QN}^{+} \mathrm{OH}^{-}\right)$, também há a formação de alcóxidos, mediante a adsorção de álcool na superfície do catalisador (Figura 1b). Já os catalisadores ácidos de BrönstedLowry, homogêneos ou heterogêneos, são capazes de protonar o grupamento carbonila dos materiais graxos, levando à formação de carbocátions (Figura 1c). ${ }^{7}$

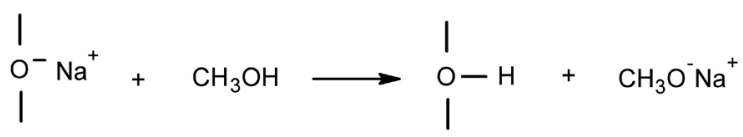

(b)

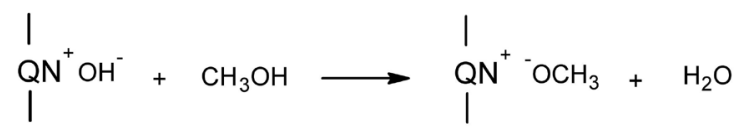

(c)

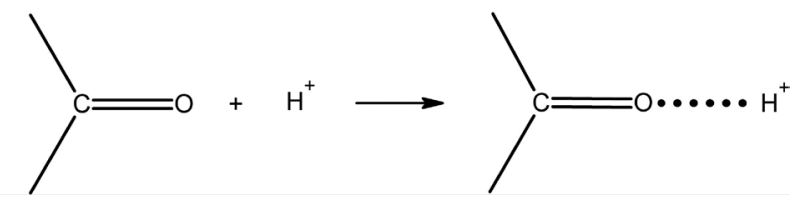

Figura 1. Fenômenos de interação em catalisadores de Brönsted-Lowry: (a) interação de alcoóis com a superfície de uma zeólita básica; (b) adsorção de alcoóis na superfície de sólidos ácidos contendo sais de amônio quaternário; (c) protonação do grupo carbonila de materiais graxos por um ácido de Brönsted-Lowry

Sólidos que possuem sítios ácidos e/ou básicos de Lewis estão entre os mais testados como catalisadores em potencial para a produção do biodiesel. Para uma melhor racionalização da ação destes catalisadores, é apresentado a seguir o mecanismo geralmente associado à ação de ácidos de Lewis em reações de esterificação (Figura 2) e de bases de Lewis em reações de transesterificação (Figura 3). ${ }^{8}$

Na Figura 2 pode ser observado que as moléculas de ácidos graxos são adsorvidas na superfície do catalisador e, devido à interação ácido-base entre o par de elétrons do oxigênio carbonílico do ácido graxo e o metal presente na estrutura do catalisador, há um aumento na densidade de carga positiva no carbono carbonílico, favorecendo o ataque nucleofílico do par de elétrons da hidroxila alcoólica com a consequente formação de um intermediário tetraédrico. Este intermediário elimina uma molécula de água e o monoéster graxo formado permanece adsorvido na superfície do catalisador. Com a desorção do monoéster, a superfície do catalisador fica livre para participar dos próximos ciclos catalíticos.

Já na Figura 3 pode ser observada a interação entre o sítio básico de Lewis do catalisador com uma molécula de álcool em uma reação de transesterificação. Esta interação ácido-base favorece o ataque nucleofílico do par de elétrons do oxigênio da hidroxila alcoólica

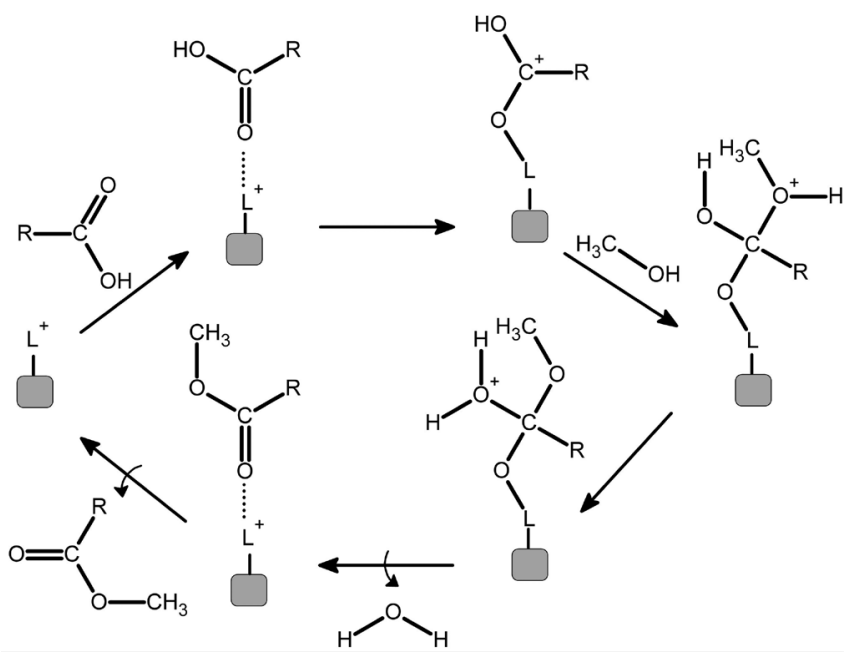

Figura 2. Mecanismo de esterificação em meio heterogêneo. " $L$ " representa o sítio ácido de Lewis e " $R$ ", o radical do ácido graxo

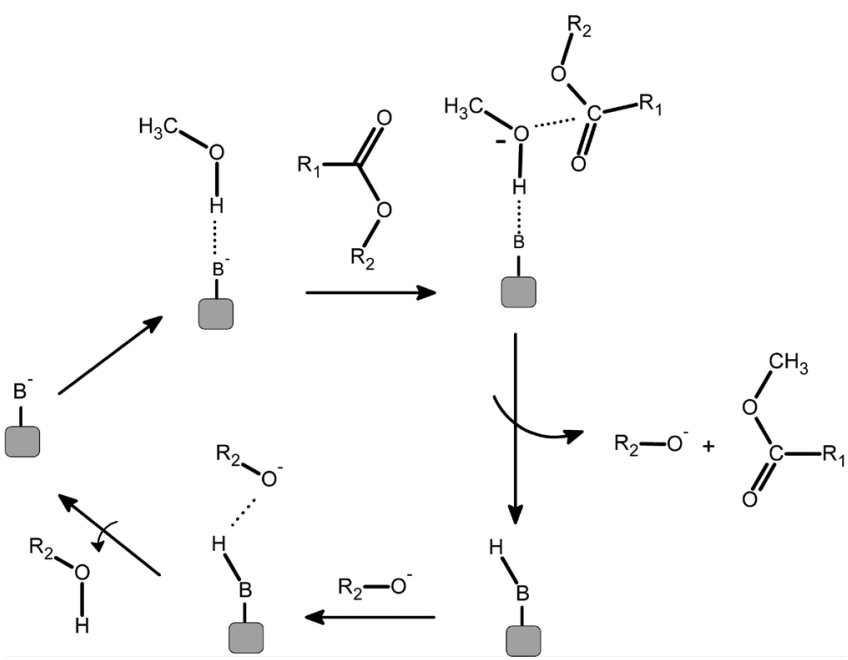

Figura 3. Mecanismo de transesterificação em meio heterogêneo. " $B$ " representa o sítio básico de Lewis, " $R$ ” $e$ " $R_{I}$ ” são radicais

ao carbono da carbonila do éster reagente, com a consequente formação de um intermediário tetraédrico que vai dar origem a outra molécula de éster e um íon alcóxido. O alcóxido remove um próton da superfície do catalisador, com a formação de outra molécula de álcool, regenerando assim o sítio básico do sólido catalítico, que fica novamente disponível para participar de um novo ciclo de catálise.

Neste trabalho, uma ampla revisão foi realizada sobre catalisadores heterogêneos que apresentam potencial para a produção do biodiesel, seja por processos de esterificação ou de transesterificação. Para facilitar a discussão, tais catalisadores foram divididos nas seguintes classes: zeólitas, óxidos e sais inorgânicos, compostos de coordenação e líquidos iônicos, resinas trocadoras de íons, ácidos e bases orgânicos e materiais lamelares, sendo que este último inclui os hidroxissais lamelares (HSLs), os carboxilatos lamelares, os hidróxidos duplos lamelares (HDLs) e os óxidos estruturados (LDOs) oriundos da calcinação controlada de HDLs.

\section{ZEÓLITAS}

Classicamente, o termo zeólita vinha sendo aplicado a aluminossilicatos cristalinos hidratados de estrutura aberta, constituídos por tetraedros de $\mathrm{SiO}_{4}$ e $\mathrm{AlO}_{4}$ ligados entre si por átomos de oxigênio. ${ }^{9-11}$ No entanto, esta definição foi recentemente expandida para 
qualquer estrutura tridimensional contendo átomos tetraedricamente coordenados (átomos T) uns aos outros através de átomos de oxigênio compartilhados, onde a densidade estrutural seja menor do que o limite de 21 átomos $\mathrm{T}$ por $1000 \AA{ }^{12}$ Estes materiais podem ser aplicados como catalisadores em reações que envolvam moléculas com diâmetro cinético inferior ao tamanho de seus poros, que são da ordem de $1 \mathrm{~nm} .{ }^{13} \mathrm{~A}$ difusão molecular sobre a superfície das zeólitas é imprescindível quando estes materiais são utilizados como catalisadores heterogêneos ou mesmo como adsorventes. A razão disso se deve ao fato de que a grande maioria dos centros ativos das zeólitas está situada no interior de seus poros.

Vários autores utilizaram zeólitas, bem como materiais obtidos por impregnação de metais em sua estrutura, como catalisadores heterogêneos para produção de biodiesel. Por exemplo, uma zeólita do tipo $\mathrm{H}$, em razão $\mathrm{Si} / \mathrm{Al}$ não fornecida pelos autores, propiciou rendimentos da ordem de 59\% quando utilizada na metanólise do óleo de Pongamia pinnata, sendo que a reação foi conduzida a 120 ${ }^{\circ} \mathrm{C}$ por 24 h com RM de $10: 1 .{ }^{14}$

Sabe-se que os sítios ácidos de Brönsted-Lowry são responsáveis pelo efeito catalítico em zeólitas $\mathrm{H} \beta$ e a força ácida destes sítios pode ser intensificada pela modificação do material com cátions como o $\mathrm{La}^{3+}$. Neste sentido, uma zeólita $\mathrm{H} \beta$, com razão $\mathrm{Si} / \mathrm{Al}$ de 3,90, e outra impregnada com $\mathrm{La}^{3+}$, com razão $\mathrm{Si} / \mathrm{Al}$ de 4,17, foram utilizadas como catalisadores de metanólise do óleo de soja, ${ }^{15}$ sendo que o monitoramento do aumento dos sítios ácidos de Brönsted-Lowry foi acompanhado por métodos espectroscópicos. Como resultado, a maior acidez do sólido modificado foi justificada pela presença de sítios dos tipos Si-OH-La e La-OH. O rendimento em monoésteres, obtido com a zeólita modificada, foi de 48,9\% na condição ótima de reação, empregando $\mathrm{RM}$ de $14,5: 1,11 \%$ de catalisador em relação à massa de óleo e agitação por $4 \mathrm{~h}$ a $60^{\circ} \mathrm{C}$.

A comparação dos resultados obtidos nos dois artigos supracitados é difícil por várias razões, como a falta da razão $\mathrm{Si} / \mathrm{Al}$ no primeiro artigo, a utilização de diferentes materiais graxos como substrato e o uso de diferentes condições de experimentais. Entretanto, o rendimento obtido com a zeólita impregnada com íons $\mathrm{La}^{3+}$ foi muito próximo do resultado obtido com a zeólita $H \beta$, apesar de que a reação catalisada pela zeólita modificada foi realizada em condições mais brandas. Desta forma, acredita-se que a presença de $\mathrm{La}^{3+}$ intensifica os sítios ácidos de Brönsted-Lowry, favorecendo o fenômeno de catálise. Porém, para comprovação desta hipótese, seria necessária a comparação de resultados obtidos nas mesmas condições de reação.

Outro fator relevante para a resposta catalítica de zeólitas em reações de alcoólise é o diâmetro de seus poros. Segundo Schuchardt e colaboradores, o diâmetro dos poros de zeólitas do tipo HY é muito pequeno para permitir a difusão interna de triacilglicerois, fazendo com que o fenômeno ocorra majoritariamente na sua superfície. ${ }^{4}$ Como o diâmetro de poros de zeólitas $\mathrm{H} \beta$ é ainda menor que os de zeólitas HY, a acessibilidade do substrato aos sítios catalíticos distribuídos internamente em sua estrutura também é limitada e a modificação química mencionada acima não parece ter sido suficiente para compensar tal limitação difusional. ${ }^{16}$

Os sítios básicos das zeólitas estão relacionados com a ponte $\mathrm{Si}(\mathrm{OH}) \mathrm{Al}$ e a permuta de hidrogênios por metais alcalinos e/ou alcalino-terrosos é o que torna o sítio básico disponível. Desta forma, a impregnação de óxidos de metais alcalinos e alcalino-terrosos, mediante o uso dos óxidos correspondentes, tem sido utilizada como estratégia para intensificar a força de seus sítios catalíticos básicos. Um exemplo disso é a impregnação da zeólita $\mathrm{KL}$ com $\mathrm{K}_{2} \mathrm{O}$, obtido da calcinação de $\mathrm{KNO}_{3}$. O material assim obtido forneceu rendimentos de 71,4\% na alcoólise do óleo de semente de noz e de 77,2\% na alcoólise do óleo de palma refinado. As reações foram realizadas por $4 \mathrm{~h}$ a $200{ }^{\circ} \mathrm{C}$ com RM de $6: 1$ e agitação orbital de $350 \mathrm{rpm} .{ }^{17}$
Zeólitas básicas, do tipo ETS-10 e NaX, foram utilizadas por Suppes e colaboradores para a metanólise do óleo de soja. ${ }^{18}$ Conversões superiores a $90 \%$ em monoésteres metílicos foram obtidas para ambos os catalisadores. As reações foram conduzidas por $24 \mathrm{~h}$ a 150 ${ }^{\circ} \mathrm{C}$ para a zeólita $\mathrm{NaX}$ e a $120{ }^{\circ} \mathrm{C}$ para a zeólita ETS-10. Na estrutura da zeólita ETS-10 existem octaedros de titânio ( $\left.\mathrm{TiO}_{6}{ }^{8-}\right)$ e tetraedros de silício $\left(\mathrm{SiO}_{4}^{4-}\right)$. A carga elevada desses octaedros, presentes na zeólita ETS-10 e ausentes na NaX, faz com que a ETS-10 possua uma maior capacidade de troca, o que certamente explica o seu melhor desempenho catalítico em comparação à zeólita $\mathrm{NaX}$.

Ramos e colaboradores empregaram um catalisador misto, à base de 35\% de zeólita NaX e $65 \%$ de bentonita sódica, para a metanólise do óleo de girassol. ${ }^{19}$ Quando as reações foram conduzidas com RM de $6: 1$ e $10 \%$ de catalisador a $65^{\circ} \mathrm{C}$ por $7 \mathrm{~h}$, os rendimentos obtidos com o catalisador misto $(95,1 \%)$ foram apenas $2 \%$ superiores ao emprego direto da zeólita $\mathrm{NaX}$ pura.

\section{ÓXIDOS E SAIS INORGÂNICOS}

Óxidos inorgânicos têm sido amplamente investigados como catalisadores para produção de biodiesel, sendo comum o uso de óxidos simples ou mistos, que podem ser obtidos pela calcinação de um sal na presença do óxido de interesse. Neste sentido, a utilização de suportes como $\mathrm{Al}_{2} \mathrm{O}_{3}$ ou $\mathrm{SiO}_{2}$ tem sido comum. Porém, poucos estudos se dedicam a investigar a possível lixiviação das espécies catalíticas presentes nestes materiais inorgânicos, quando empregados em processos de síntese de biodiesel. Além disto, a reciclagem, a caracterização química após o uso e a lixiviação de espécies químicas que promovam processos homogêneos não têm sido enfatizadas na literatura.

$\mathrm{O}$ produto da impregnação de diferentes concentrações de $\mathrm{KNO}_{3}$ em alumina $\left(\mathrm{Al}_{2} \mathrm{O}_{3}\right)$, realizada a $120^{\circ} \mathrm{C}$ por $16 \mathrm{~h}$, foi utilizado como catalisador heterogêneo para produção de biodiesel. ${ }^{20} \mathrm{O}$ melhor rendimento em monoésteres foi de $87 \%$ utilizando RM metanol:óleo de 15:1, aquecimento sob refluxo por $7 \mathrm{~h}$ e $6,5 \%$ de um catalisador contendo $35 \%$ de $\mathrm{KNO}_{3}$ suportado em alumina. Além do $\mathrm{KNO}_{3}$, soluções aquosas de $\mathrm{K}_{2} \mathrm{CO}_{3}$ também foram utilizadas para impregnação de potássio em alumina e o material calcinado foi utilizado na metanólise do óleo de girassol. ${ }^{21}$ Rendimentos da ordem de $99 \%$ em monoésteres metílicos foram obtidos em $1 \mathrm{~h}$ de reação, com RM de 25:1 e 3\% de catalisador em relação à massa de material graxo. Experimentos de reuso do catalisador, nas mesmas condições supracitadas, demonstraram que os rendimentos diminuíram para 33; 6,5 e $3,8 \%$ quando este foi utilizado pela segunda, terceira e quarta vez, respectivamente. Conclui-se, portanto, que os materiais sólidos estavam apenas impregnados com espécies catalíticas que, uma vez lixiviadas para o meio de reação, atuaram de forma homogênea na síntese dos monoésteres graxos.

A atividade catalítica do metóxido de cálcio foi investigada em reações de metanólise do óleo de soja. O alcóxido foi sintetizado pela dissolução de cálcio elementar em metanol e posterior secagem até massa constante. As melhores condições de síntese foram obtidas com razão volumétrica metanol:óleo de 1:1 e 2\% de catalisador a $65{ }^{\circ} \mathrm{C}$ por $2 \mathrm{~h}$. Nestas condições, foi observada conversão total dos triacilglicerois em monoésteres metílicos. ${ }^{22}$

Diferentes métodos de obtenção de $\mathrm{CaO}$ têm sido utilizados para a produção de biodiesel e a resposta catalítica destes sólidos parece depender do método de preparação, bem como das condições de reação empregadas. Por exemplo, quando amostras de $\mathrm{CaO}$ foram testadas na metanólise do óleo de soja, rendimentos da ordem de $95 \%$ foram obtidos em $3 \mathrm{~h}$ a $65^{\circ} \mathrm{C}$ com $8 \%$ de catalisador e RM de 12:1. Segundo estes autores, o desempenho catalítico do $\mathrm{CaO}$ manteve-se constante ao longo de dez ciclos consecutivos de reação, sem perdas significativas de rendimento. ${ }^{23}$ 
Nakatani e colaboradores utilizaram o óxido de cálcio, oriundo da calcinação do carbonato de cálcio a $700{ }^{\circ} \mathrm{C}$, como catalisador para a metanólise do óleo de soja. ${ }^{24}$ Foram obtidas amostras de monoésteres com pureza da ordem de $99 \%$, utilizando $20 \%$ de catalisador e RM de $6: 1$ por $4 \mathrm{~h}$ a $65^{\circ} \mathrm{C}$.

Kouzu e colaboradores empregaram $\mathrm{Ca}(\mathrm{OH})_{2}$ e $\mathrm{CaO}$, obtido mediante calcinação do carbonato de cálcio a $900{ }^{\circ} \mathrm{C}$ por $1,5 \mathrm{~h}$, para catalisar a metanólise do óleo de soja. ${ }^{25}$ Depois de $1 \mathrm{~h}$ de reação, rendimentos de $93 \%$ foram obtidos com $\mathrm{CaO}$ e de $12 \%$ com $\mathrm{Ca}(\mathrm{OH})_{2}$, enquanto que o $\mathrm{CaCO}_{3}$ não apresentou atividade catalítica. Quando o sistema foi mantido em reação por $2 \mathrm{~h}$, o rendimento obtido foi de 99\%, porém, a quantidade de sabões de cálcio passou de 187 para 3065 ppm. Em ambos os casos, as reações foram conduzidas em aquecimento sob refluxo do metanol, com RM de 12:1 e $14 \mathrm{mmol}$ de catalisador para cada $100 \mathrm{~mL}$ de óleo.

$\mathrm{O} \mathrm{CaO}$ previamente suportado em sólidos mesoporosos foi utilizado como catalisador heterogêneo em reações de transesterificação metílica. Os melhores resultados foram obtidos utilizando $14 \%$ de cálcio impregnado em sílica SBA que, a $1 \%$ de catalisador e RM de $12: 1$ a $60{ }^{\circ} \mathrm{C}$, forneceu rendimentos de $65,7 \%$ com óleo de mamona e de $95 \%$ com óleo de girassol após 1 e 5 h de reação, respectivamente. Nestes experimentos, não foi detectada nenhuma evidência de lixiviação do catalisador para o meio de reação. ${ }^{26}$

Os catalisadores $\mathrm{CaTiO}_{3}, \mathrm{CaMnO}_{3}, \mathrm{Ca}_{2} \mathrm{Fe}_{2} \mathrm{O}_{5}, \mathrm{CaZrO}_{3}$ e $\mathrm{CaO}$ $\mathrm{CeO}_{2}$ apresentaram elevada atividade catalítica na metanólise alcalina do óleo de colza em meio heterogêneo. Os catalisadores foram ativados por calcinação antes do uso e os testes foram realizados a $60{ }^{\circ} \mathrm{C}$ por $10 \mathrm{~h}$ com RM de $6: 1$, proporcionando rendimentos da ordem de $90 \%$. Os testes de reuso, de 5 a 7 para alguns catalisadores testados, mostraram que estes materiais apresentam elevada durabilidade e, portanto, grande potencial para uso na síntese de biodiesel. ${ }^{27}$

$\mathrm{O} \mathrm{CaO}$ dopado com lítio mostrou-se cataliticamente ativo na metanólise do óleo de girassol. ${ }^{28}$ A quantidade mínima de lítio necessária para que o sólido resultante apresentasse atividade catalítica foi de $4,5 \%$. Além disso, a ativação do catalisador exigiu calcinação em temperaturas superiores a $219^{\circ} \mathrm{C}$, que é a temperatura de fusão do $\mathrm{LiNO}_{3}$. O material calcinado a $700{ }^{\circ} \mathrm{C}$ forneceu rendimentos de $87 \%$ quando a reação foi conduzida a $60^{\circ} \mathrm{C}$ por $3 \mathrm{~h}$, com RM metanol:óleo de $14: 1$ e $0,2 \%$ de catalisador.

Uma melhora significativa do desempenho catalítico do $\mathrm{CaO}$ pode ser obtida utilizando-se materiais com maior área superficial e disponibilidade de sítios catalíticos. Reddy e colaboradores utilizaram nanocristais de $\mathrm{CaO}$ (20 nm de diâmetro e $90 \mathrm{~m}^{2} / \mathrm{g}$ de área superficial) na metanólise do óleo de soja e obtiveram conversões de $100 \%$ do material graxo em monoésteres metílicos, quando a reação foi conduzida na temperatura ambiente por $12 \mathrm{~h} .{ }^{29} \mathrm{O}$ melhor desempenho catalítico destes nanocristais, quando comparado ao de outros óxidos de cálcio, foi atribuído à sua maior área superficial.

O óxido de zinco foi utilizado como catalisador da metanólise do óleo de Pongamia pinnata. ${ }^{14} \mathrm{O}$ melhor resultado obtido foi de $83 \%$ quando as condições corresponderam a uma RM de 10:1, 10\% de catalisador e aquecimento a $120^{\circ} \mathrm{C}$ por $24 \mathrm{~h}$ de reação.

Materiais obtidos da coprecipitação de alumina e óxidos de estanho e zinco foram utilizados como sistemas catalíticos para alcoólise de óleos vegetais. Observou-se que óxidos metálicos do tipo $\left(\mathrm{Al}_{2} \mathrm{O}_{3}\right)_{\mathrm{x}}(\mathrm{SnO})_{\mathrm{y}}(\mathrm{ZnO})_{\mathrm{z}}$ são ativos para a alcoólise do óleo de soja usando diversos alcoóis, incluindo os ramificados. Os melhores resultados foram obtidos com metanol, que permitiu atingir conversões acima de $80 \%$ em 4 h utilizando $10 \mathrm{~g}$ de óleo de soja, 1,5 g de álcool e 0,5 $\mathrm{g}$ de catalisador. Foi também possível reutilizar estes materiais sem perda aparente de sua atividade catalítica. ${ }^{30}$

Uma espécie cataliticamente ativa na metanólise do óleo de soja foi produzida pela calcinação, a $600{ }^{\circ} \mathrm{C}$ por $5 \mathrm{~h}$, de uma mistura contendo 2,5 mmol de nitrato de estrôncio por grama de óxido de zinco. ${ }^{8} \mathrm{O}$ catalisador foi testado a $5 \%$ em relação à massa de óleo com RM de 12:1 sob refluxo, fornecendo rendimentos da ordem de 94,7\% na ausência e de 96,8\% na presença de tetra-hidrofurano (THF) como cossolvente para melhorar a miscibilidade entre o metanol e o óleo. No entanto, o uso de cossolventes não é uma prática comum em trabalhos de investigação sobre a alcoólise.

Sunita e colaboradores empregaram isopoli- e heteropoli-tungstatos suportados em zircônia na metanólise do óleo de girassol. ${ }^{31} \mathrm{~A}$ zircônia suportada com isopoli-tungstato mostrou atividade catalítica superior à suportada com heteropoli-tungstato. Quando a reação foi conduzida a $200{ }^{\circ} \mathrm{C}$, com RM de $15: 1$ e $15 \%$ do catalisador suportado em isopoli-tungstato $\left(\mathrm{WO}_{3} / \mathrm{ZrO}_{2}\right)$ e calcinado a $750{ }^{\circ} \mathrm{C}$, o rendimento foi da ordem de $97 \%$.

Garcia e colaboradores utilizaram duas zircônias sulfatadas como catalisadores na alcoólise do óleo de soja e na esterificação do ácido oleico. ${ }^{32} \mathrm{O}$ catalisador $\mathrm{S}-\mathrm{ZrO}_{2}$ foi obtido pelo método livre de solvente e forneceu conversões de $98,6 \%$ na metanólise e de $92 \%$ na etanólise do óleo de soja, ambas realizadas a $120^{\circ} \mathrm{C}$ por $1 \mathrm{~h}$ com $5 \%$ de catalisador. Sob estas mesmas condições, a esterificação metílica do ácido oleico se completou em $2 \mathrm{~h}$. No entanto, os resultados foram bem mais modestos quando o catalisador foi obtido pelo método de precipitação tradicional, sendo obtidas conversões de apenas 8,5\% em ésteres metílicos a partir do óleo de soja.

A atividade catalítica de uma mistura de óxidos de zinco e lantânio obtidos pelo método da coprecipitação foi testada em reações de transesterificação, bem como em um processo simultâneo de esterificação e transesterificação, utilizando óleo de soja refinado e materiais graxos de elevada acidez. Rendimentos superiores a $90 \%$ foram obtidos na metanólise do óleo de soja em $1 \mathrm{~h}$ e $40 \mathrm{~min}$, a partir de uma mistura de óxidos com razão $\mathrm{Zn} /$ La de 3 . A reação foi realizada a $200{ }^{\circ} \mathrm{C}$ com $126 \mathrm{~g}$ de óleo, 180 $\mathrm{g}$ de metanol e $3 \mathrm{~g}$ de catalisador. $\mathrm{O}$ mesmo catalisador também foi utilizado em uma mistura de $5,4 \%(\mathrm{~m} / \mathrm{m})$ de ácido oleico e $94,6 \%(\mathrm{~m} / \mathrm{m})$ de óleo de soja, sendo a reação conduzida a $200{ }^{\circ} \mathrm{C}$ na presença de excesso de metanol. Neste caso, o rendimento foi de aproximadamente $95 \%$ em $1 \mathrm{~h}$ de reação. ${ }^{33}$

$\mathrm{O}$ molibdato de sódio anidro $\left(\mathrm{Na}_{2} \mathrm{MoO}_{4}\right)$ foi investigado como catalisador heterogêneo para a metanólise do óleo de soja refinado. ${ }^{34} \mathrm{~A}$ reação alcançou rendimentos de $95 \%$ sob as seguintes condições: $5,0 \%$ de catalisador em relação à massa de óleo, RM de 54:1 e 3 h de reação sob refluxo. Os monoésteres produzidos foram caracterizados sem a necessidade de qualquer tipo de purificação e o reuso do catalisador apresentou um decréscimo médio de 11,4\% no rendimento das reações após cada ciclo. Esta redução foi justificada pelos autores como perdas mecânicas ocorridas durante as etapas de separação e transferência; no entanto, a eventual lixiviação de espécies catalíticas para o meio de reação não foi avaliada neste estudo.

O óxido de nióbio apresenta atividade catalítica em vários tipos de reações orgânicas, tais como esterificação, metátase, hidrólise, condensação, alquilação, oxidação, entre outras. ${ }^{35}$ Recentemente, Aranda e colaboradores investigaram o uso do óxido de nióbio como catalisador heterogêneo para a esterificação de ácidos graxos derivados do refino do óleo de palma, utilizando metanol e etanol como agentes acilantes. ${ }^{36} \mathrm{Em}$ um procedimento típico, foram utilizados $307 \mathrm{~g}$ de ácidos graxos, 3,2\% de catalisador e $149 \mathrm{~mL}$ de metanol ou $215 \mathrm{~mL}$ de etanol. Os experimentos foram conduzidos em reator pressurizado a $130{ }^{\circ} \mathrm{C}$, com rendimentos da ordem de 80 e $20 \%$ nas reações de esterificação com metanol e etanol, respectivamente. Tal processo, patenteado por este mesmo grupo de pesquisa, serviu como base tecnológica para a instalação de uma unidade industrial de produção de biodiesel no Estado do Pará. 


\section{COMPOSTOS DE COORDENAÇÃO}

Diversos complexos bimetálicos de cianeto (designados como $\mathrm{Fe}^{2+}-\mathrm{M}^{2+}$, onde $\mathrm{M}^{2+}$ corresponde a $\mathrm{Zn}^{2+}, \mathrm{Cu}^{2+}, \mathrm{Ni}^{2+} \mathrm{Ou} \mathrm{Co}^{2+}$ ), baseados na impregnação de copolímeros de polietileno glicol e polipropileno glicol com massa molar média de $5800 \mathrm{~g} / \mathrm{mol}$, foram testados como catalisadores da alcoólise de triacilglicerois e da esterificação do ácido oleico ${ }^{37}$ Estes materiais foram preparados por precipitação a partir de soluções aquosas de $\mathrm{K}_{4} \mathrm{Fe}(\mathrm{CN})_{6} \cdot 3 \mathrm{H}_{2} \mathrm{O}$ e de diferentes cloretos $\left(\mathrm{ZnCl}_{2}\right.$, $\mathrm{CuCl}_{2} \cdot 2 \mathrm{H}_{2} \mathrm{O}, \mathrm{NiCl}_{2} \cdot 6 \mathrm{H}_{2} \mathrm{O}$ e $\left.\mathrm{CoCl}_{2} \cdot 6 \mathrm{H}_{2} \mathrm{O}\right)$, empregando $t$-butanol como cossolvente. Enquanto os complexos $\mathrm{Fe}^{2+}-\mathrm{Cu}^{2+}, \mathrm{Fe}^{2+}-\mathrm{Ni}^{2+}$ e $\mathrm{Fe}^{2+}-\mathrm{Co}^{2+}$ apresentaram baixa atividade catalítica na metanólise do óleo de girassol refinado, nas condições de $3 \%$ de catalisador em relação à massa de óleo, RM de $15: 1$ e $170{ }^{\circ} \mathrm{C}$ por $8 \mathrm{~h}$, o complexo $\mathrm{Fe}^{2+}-\mathrm{Zn}^{2+}$ permitiu a obtenção de conversões de 98,3; 98,0; 97,9 e 98,1\% em quatro ciclos consecutivos de reação. Quando comparada com os outros sólidos testados, a melhor atividade catalítica do complexo $\mathrm{Fe}^{2+} / \mathrm{Zn}^{2+}$ foi atribuída à sua maior concentração de sítios ácidos de Lewis, conforme demonstrado pelos resultados de adsorção de $\mathrm{NH}_{3}$. Nestas mesmas condições, este catalisador também apresentou excelente atividade catalítica na etanólise da margarina (99\%), bem como na metanólise dos óleos de coco $(99,8 \%)$, palma $(98,3 \%)$, gergelim $(98,2 \%)$, amendoim $(97 \%)$, açafroa (97\%), margarina (98,9\%), margarina usada (98\%), mamona $(78,3 \%)$, semente de seringueira $(97,1 \%)$, pinhão-manso $(86,9 \%)$, Calophyllum sp. $(84,2 \%)$ e karanja $(88,3 \%)$. Além disso, a aplicação do complexo $\mathrm{Fe}^{2+}-\mathrm{Zn}^{2+}$ na esterificação metílica do ácido oleico promoveu conversões de $92,2 \%$ após 12 h de reação com $3 \%$ de catalisador em relação à massa de ácido e RM álcool:ácido de 2:1. Além disto, a atividade catalítica deste material não foi afetada de forma significativa pela adição de água na mistura de reação, em proporções que variaram de 1 a 20\% em relação à massa de óleo originalmente empregada.

\section{LÍQUIDOS IÔNICOS}

O líquido iônico 1- $n$-butil-3-metilimidazol tetracloro-indano $\left(\mathrm{BMI} . \mathrm{InCl}_{4}\right)$ foi utilizado como catalisador heterogêneo na transesterificação (m)etílica do óleo de soja. Rendimentos da ordem de 84\% foram obtidos quando o metal complexado foi o estanho. A reação foi conduzida utilizando-se $3 \mathrm{~g}$ de metanol para cada $10 \mathrm{~g}$ de óleo por 10 h a $80^{\circ} \mathrm{C}$, sob agitação magnética e refluxo. Em condições análogas, a etanólise forneceu rendimentos da ordem de $42 \%{ }^{38}$

Outro líquido iônico, o cloroaluminato de trietilamina, também foi testado na metanólise do óleo de soja previamente purificado e seco, com acidez inferior a $0,3 \mathrm{mg} \mathrm{KOH} / \mathrm{g}$ e umidade inferior a $10 \mathrm{ppm} .{ }^{39}$ A exigência por óleos de baixa acidez e baixa umidade foi justificada pelos autores em função da natureza do fenômeno catalítico, que envolve os grupamentos amino presentes na estrutura. $\mathrm{O}$ catalisador se mostrou altamente ativo sob RM metanol:óleo de 12:1, $5 \mathrm{mmol}$ de catalisador e $70{ }^{\circ} \mathrm{C}$ por $9 \mathrm{~h}$ sob agitação magnética, fornecendo uma taxa de conversão de $98,5 \%$. Este catalisador foi reutilizado por até seis ciclos de reação sem perda de sua atividade catalítica, após separação do meio de reação e lavagem com acetato de etila. Por outro lado, o catalisador se mostrou altamente sensível à presença de acidez e umidade na amostra, sendo observado um decréscimo de até $50 \%$ na taxa de conversão e grande formação de sabões, além de sua decomposição parcial quando se empregou um óleo de soja com acidez de $15 \mathrm{mg} \mathrm{KOH} / \mathrm{g}$ e umidade de 10.000 ppm.

Zhang e colaboradores sintetizaram biodiesel pela esterificação metílica do ácido oleico utilizando como catalisador o metil sulfonato de N-metil-2-pirrolidona, um ácido de Brönsted. ${ }^{40}$ Obtiveram-se rendimentos de $95 \%$ quando as esterificações foram conduzidas a $70{ }^{\circ} \mathrm{C}$ por $8 \mathrm{~h}$. As reações foram conduzidas com RM metanol:ácido oleico:catalisador de 2:1:0,338.

\section{RESINAS TROCADORAS DE ÍONS}

Vários tipos de resinas trocadoras de íons (RTI) têm sido empregados como catalisadores heterogêneos em reações de esterificação de ácidos graxos e de alcoólise de óleos e gorduras. ${ }^{41}$

A resina SAC-13 possui um caráter fortemente ácido, sendo constituída de um polímero fluorssulfônico ácido $\left(\mathrm{Nafion}^{\circledR}\right)$ suportado em sílica amorfa, com 10-20\% de poros em escala nanométrica e densidade de sítios ácidos de $0,129 \mathrm{mmol} / \mathrm{g}$. Esta resina foi utilizada como catalisador na esterificação metílica do ácido palmítico na presença de óleo de girassol refinado. ${ }^{42}$ Os experimentos foram realizados em reatores do tipo batelada, adicionando-se $30 \mathrm{~mL}$ de óleo de girassol contendo $10 \%$ em massa de ácido palmítico e 9 $\mathrm{mL}$ de metanol contendo $1 \mathrm{~g}$ de catalisador. Os experimentos foram conduzidos a $60^{\circ} \mathrm{C}$ e $1000 \mathrm{rpm}$ por $3 \mathrm{~h}$ em pressão ambiente. A taxa de conversão do ácido palmítico foi de $47 \%$ no primeiro ciclo de reação, mantendo-se em torno de $40 \%$ até o quarto ciclo. Também foram conduzidos experimentos em reator de leito fixo contendo $2 \mathrm{~g}$ de resina, através do qual foi percolado um meio de reação composto por $6 \mathrm{~mL}$ da mistura de óleo de girassol/ácido palmítico e $18 \mathrm{~mL}$ de metanol. O sistema foi mantido a uma vazão de $6,1 \mathrm{~mL} / \mathrm{s}$ por $48 \mathrm{~h} \mathrm{e}$, nestas condições, a conversão de ácido palmítico em éster metílico foi de aproximadamente $97 \%$ no primeiro ciclo de reação e $85 \%$ após o quarto ciclo.

Três resinas de troca iônica da Röhm and Hass ${ }^{\circledR}$ (hoje subsidiária da Dow Chemical ${ }^{\circledR}$ ), sendo duas aniônicas (Amberlyst ${ }^{\circledR}$ A26 e A27) e uma catiônica (Amberlyst ${ }^{\circledR} 15$ ), foram testadas na transesterificação metílica de óleo de girassol refinado. ${ }^{43}$ Os experimentos foram conduzidos a $60{ }^{\circ} \mathrm{C}$ sob pressão atmosférica e taxa de agitação de 600 rpm por $8 \mathrm{~h}$. Ao serem empregados $1 \%$ de catalisador em relação à massa de óleo e RM álcool:óleo de 6:1, percentuais extremamente baixos de conversão em monoésteres foram obtidos: 0,1\% com Amberlyst $^{\circledR}$ A26, 0,4\% com Amberlyst ${ }^{\circledR}$ A27 e $0,7 \%$ para a Amberlyst ${ }^{\circledR}$ 15 , demonstrando que, nas condições testadas, estas resinas não se apresentaram como bons catalisadores para reações de alcoólise.

Diferentes suportes à base de estireno (S) e divinilbenzeno (DVB) foram sintetizados por polimerização em suspensão aquosa, empregando teores variados de DVB (10, 20, 40 e 60\%), graus de diluição (GD) de 100 e $150 \%$ em relação ao volume de fase monomérica e tolueno ou $n$-heptano como solventes. ${ }^{44} \mathrm{~A}$ partir destes suportes, foram preparados um copolímero não sulfonado e diferentes resinas sulfônicas com capacidade de troca entre 3,7 e $5,7 \mathrm{meq}_{\mathrm{SO}_{3} \mathrm{H}} / \mathrm{g}_{\text {cat }}$, cujos desempenhos na metanólise do óleo de coco de babaçu foram comparados ao da resina catiônica Amberlyst ${ }^{\circledR} 15$. As reações foram realizadas utilizando RM de 300:1, $1 \%$ de catalisador em relação à massa de óleo e agitação magnética por $8 \mathrm{~h}$ sob refluxo. O copolímero não sulfonado não apresentou atividade catalítica alguma e o melhor resultado foi obtido com a resina de $4,4 \mathrm{meq}_{\mathrm{so}_{3} \mathrm{H}} / \mathrm{g}_{\text {cat }}$, sintetizada em GD de $100 \%$ na presença de $40 \%$ de DVB. Nas mesmas condições experimentais, esta resina apresentou desempenho catalítico análogo à Amberlyst ${ }^{\circledR} 15$ (72 contra $80 \%$ da resina comercial), cuja capacidade de troca era de $5,5 \mathrm{meq}_{\mathrm{SO}_{3} \mathrm{H}} / \mathrm{g}_{\text {cat }}$. Embora a capacidade de troca das resinas sintetizadas tenha diminuído com o aumento do teor de DVB, a atividade catalítica não dependeu exclusivamente desta propriedade. Outros fatores também influenciaram o desempenho das resinas, como a densidade, o grau de inchamento em água e metanol e a regularidade da estrutura tridimensional e porosa.

Experimentos análogos foram realizados com RTI sulfonadas que foram sintetizadas, na presença de 1,2-dicloroetano (DCE) ou nitrometano (NM), a partir de poli(S-DVB) ou poli(DVB) com GD de 150 ou $200 \% .{ }^{45}$ A metanólise do óleo de coco de babaçu em RM metanol:óleo de 100:1, com resinas poli(S-DVB) sintetizadas na presença de DCE, forneceu conversões de 77 e $97 \%$ quando a síntese do 
suporte utilizou matrizes com GD de 150 e $200 \%$, respectivamente. Ao se utilizarem resinas poli(DVB), sintetizadas na presença de NM, conversões de 65 e $75 \%$ foram observadas para os mesmos valores de $\mathrm{GD}$, respectivamente. Em comparação à Amberlyst ${ }^{\circledR} 35$, o catalisador sintético com GD de 200\% (GD200) apresentou desempenho $12 \%$ superior (99 contra $87 \%$ da resina comercial) em metanólises realizadas com RM de 150:1 e 0,5\% de catalisador. Estes autores também empregaram as resinas Amberlyst ${ }^{\circledR} 15$, Amberlyst ${ }^{\circledR} 35$ e GD200 em reações de metanólise do óleo de soja refinado. As resinas Amberlyst ${ }^{\circledR}$ 35 e GD200 forneceram conversões da ordem de 30 e 97\%, respectivamente, quando testadas sob RM metanol:óleo de soja de 300:1 e $1 \%$ de catalisador sob refluxo por $8 \mathrm{~h}$. Por outro lado, os testes com Amberlyst ${ }^{\circledR} 15$ empregaram RM de $150: 1$ e 0,5\% de catalisador sob refluxo por $8 \mathrm{~h}$ para uma conversão em monoésteres de $56 \%$.

Diferentes catalisadores ácidos poliméricos foram testados por Guerreiro e colaboradores para a metanólise do óleo de soja ${ }^{46}$ Este estudo envolveu duas membranas Nafion ${ }^{\circledR}$ (N112 e N115, da DuPont), três resinas ácidas Dowex ${ }^{\circledR}(50 \mathrm{X} 8,50 \mathrm{X} 4$ e 50X2, da Dow Chemical) e três membranas de poli(álcool vinílico) (PVA) modificadas, duas utilizando ácido sulfo-succínico como agente de ligação cruzada (PVA20 e PVA5) e outra preparada pela esterificação com ácido 5-sulfo-salicílico de $20 \%$ dos grupamentos hidroxila presentes nas ligações cruzadas da matriz de PVA (PVASS20). As reações foram realizadas sob pressão ambiente, com as resinas ácidas sendo testadas na forma de pellets esféricos com diâmetros de 0,331 mm (Dowex ${ }^{\circledR}$ 50X2), 0,314 mm (Dowex ${ }^{\circledR} 50 \mathrm{X} 4$ ) e 0,078 mm (Dowex ${ }^{\circledR}$ 50X8), enquanto que as membranas foram utilizadas na forma de pequenas placas de $1 \mathrm{~cm}^{2}$ de base e espessura média de $0,1 \mathrm{~mm}$. Os experimentos foram conduzidos em um reator com agitação magnética, com os catalisadores sendo previamente acondicionados em metanol por 24 $\mathrm{h}$ antes da adição de óleo de soja na temperatura de reação. Também foram realizados experimentos em reator contínuo com as membranas Nafion $^{\circledR}$ e PVA na forma de discos de $8 \mathrm{~cm}$ de diâmetro, as quais também foram previamente inchadas com metanol por $24 \mathrm{~h}$ antes de ser acionada a percolação de metanol e óleo de soja na temperatura de reação. Para todos os catalisadores testados na forma de pellets ou placas em reator de agitação magnética, foi observada a ocorrência de um período de indução seguido de aumento gradual na taxa de conversão. As resinas Dowex ${ }^{\circledR}$ 50X2 e PVA20 apresentaram um período de indução de $100 \mathrm{~h}$ quando o reator foi operado a $60{ }^{\circ} \mathrm{C}$ sob RM álcool:óleo de 285:1 e, após 180 e 250 h, forneceram concentrações de 0,3 e 1,1 $\mathrm{mol} / \mathrm{L}$ em monoésteres metílicos, respectivamente. No reator de membrana, o catalisador PVA5 não apresentou período de indução e forneceu, após 27 h, uma amostra com concentração em monoésteres de $0,7 \mathrm{~mol} / \mathrm{L}$ ao se empregar uma RM álcool:óleo de 120:1 a $60^{\circ} \mathrm{C}$. Com exceção desta membrana, as demais quebraram antes que fossem observadas conversões significativas.

As resinas Dowex ${ }^{\circledR}$ Monosphere 550 A e Dowex ${ }^{\circledR}$ Upcore Mono A-625 (Dow Chemical $^{\circledR}$ ) foram utilizadas como catalisadores heterogêneos na metanólise de óleo de girassol com acidez equivalente a 10,67 g de ácido oleico por $100 \mathrm{~g}$ de amostra. ${ }^{47}$ Quando as reações foram efetuadas por $120 \mathrm{~h}$ a $45^{\circ} \mathrm{C}$ com RM metanol:óleo de 6,1:1, $2,3 \%$ de catalisador em relação à massa de óleo e 200 rpm de agitação, as resinas Dowex ${ }^{\circledR}$ Monosphere 550 e Dowex ${ }^{\circledR}$ Upcore Mono A-625A apresentaram rendimentos de 75 e $20 \%$ em monoésteres metílicos, respectivamente. Acima de 120 h até o limite de 180 h, não houve variação significativa nos rendimentos de ambas as reações.

Soldi e colaboradores testaram catalisadores poliméricos, obtidos a partir da sulfonação do poliestireno linear, na alcoólise dos óleos de soja e de milho, além de sebo bovino. ${ }^{48} \mathrm{Na}$ etanólise do óleo de soja (acidez de 0,1 mg KOH/g de amostra), sob RM álcool:óleo de 100:1 e 20 mol\% de catalisador, foram obtidas conversões de $85 \%$, enquanto que o uso de metanol, nas mesmas condições de reação, forneceu conversões de $94 \%$. Na etanólise do óleo de milho bruto (acidez de 1,3 mg KOH/g de amostra), foram obtidas conversões de $75 \%$ e, ao se empregar sebo bovino (acidez de $53 \mathrm{mg}$ de $\mathrm{KOH} / \mathrm{g}$ de amostra), o percentual de conversão decresceu para $70 \%$.

\section{ÁCIDOS E BASES ORGÂNICOS}

Lou e colaboradores utilizaram o produto da pirólise de diferentes carboidratos para o desenvolvimento de catalisadores sulfonados que foram empregados em reações de metanólise de óleos residuais com $27,8 \%$ de acidez. ${ }^{49}$ Os catalisadores foram preparados pelo tratamento térmico de D-glucose, sacarose, celulose e amido que, por sulfonação, forneceram materiais com as seguintes composições químicas: $\mathrm{CH}_{1,14} \mathrm{O}_{0,39} \mathrm{~S}_{0,030}, \mathrm{CH}_{1,06} \mathrm{O}_{0,30} \mathrm{~S}_{0,029}, \mathrm{CH}_{1,01} \mathrm{O}_{0,28} \mathrm{~S}_{0,031}$ e $\mathrm{CH}_{0,85} \mathrm{O}_{0,23} \mathrm{~S}_{0,032}$, respectivamente. Quando as reações foram conduzidas com RM metanol:óleo de $20: 1$ a $80{ }^{\circ} \mathrm{C}, 500 \mathrm{rpm}$ e $10 \%$ de catalisador, foram obtidos rendimentos da ordem de $80 \%$ em intervalos que variaram de 8 a 12 h de reação, independentemente do tipo de catalisador empregado. Entretanto, rendimentos da ordem de $92 \%$ foram atingidos quando o catalisador derivado do amido foi utilizado em RM metanol:óleo de $30: 1$ e $10 \%$ de catalisador a $80^{\circ} \mathrm{C}$ por $8 \mathrm{~h}$. Nos testes de reuso com o material derivado do amido, foi possível a realização de 50 ciclos de reuso sem perda expressiva da atividade catalítica.

Melero e colaboradores desenvolveram catalisadores heterogêneos, baseados na introdução de grupamentos sulfônicos em estruturas poliméricas do tipo tetrametil-ortossilicato, para aplicação em reações de metanólise dos óleos refinados de palma e de soja. ${ }^{50}$ Rendimentos em monoésteres metílicos da ordem de $95 \%$, em relação à massa de óleo empregada na reação, foram obtidos quando as reações foram conduzidas com RM metanol:óleo de 10:1 e 6\% de catalisador a $180{ }^{\circ} \mathrm{C}$ por $2 \mathrm{~h}$.

Vários tipos de guanidinas, heterogeneizadas ou não, já foram propostas como catalisadores eficientes para a alcoólise de triacilglicerois. Schuchardt e colaboradores obtiveram rendimentos superiores a 90\% na metanólise do óleo de colza utilizando como catalisador 1 mol \% de 1,5,7-triazobiciclo-[4.4.0]-dec-5-eno e RM metanol:óleo de $6,86: 1$ a $70{ }^{\circ} \mathrm{C}$ sob refluxo por $1 \mathrm{~h} .{ }^{51}$ No entanto, rendimentos de $96 \%$ foram obtidos ao se aumentar a quantidade de catalisador para 2 mol \% e o tempo de reação para $3 \mathrm{~h}$.

O sólido obtido a partir da impregnação de 1,1,3,3-tetrametilguanidina (TMG) em sílica também foi utilizado na metanólise do óleo de soja. ${ }^{52} \mathrm{O}$ emprego de $0,5 \mathrm{~g}$ deste catalisador na alcoólise de 10,0 $\mathrm{g}$ de óleo de soja com $1,5 \mathrm{~g}$ de metanol a $80^{\circ} \mathrm{C}$ forneceu rendimento de $86,7 \%$ em 3 h de reação. A redução da massa de catalisador para $0,2 \mathrm{~g}$ promoveu uma queda de $3 \%$ no rendimento e, em experimentos de reuso, o catalisador mostrou-se ativo por 9 ciclos de reação, com rendimento de próximo de $62 \%$ nos últimos testes.

\section{HIDRÓXIDOS DUPLOS LAMELARES E ÓXIDOS ESTRUTURADOS}

Os hidróxidos duplos lamelares (HDLs) podem ser representados pela fórmula $\left[\mathrm{M}_{1-x}^{2+} M^{\beta^{+}}(\mathrm{OH})_{2}\right] A_{x / m-}^{m-} n H_{2} \mathrm{O}$, na qual $\mathrm{M}^{2+}$ representa um cátion divalente, $\mathrm{M}^{3+}$ representa um cátion trivalente e $\mathrm{A}^{\mathrm{m}-}$ representa o ânion intercalado com carga $-\mathrm{m} .{ }^{53}$ Estes materiais correspondem a compostos do tipo hidrotalcita e possuem lamelas com estruturas do tipo brucita $\left(\mathrm{Mg}(\mathrm{OH})_{2}\right)$. As lamelas da brucita são neutras, com cátions magnésio localizados no centro de octaedros regulares e grupamentos hidroxila nos vértices. Com a substituição de cátions divalentes por trivalentes, lamelas positivamente carregadas são obtidas com estrutura idêntica à das lamelas da brucita. Estas lamelas, para serem estabilizadas, necessitam da presença de ânions hidratados, os quais são intercalados entre as lamelas. ${ }^{54}$ 
O uso de HDLs como catalisadores em reações de transesterificação é menos comum em relação ao uso de óxidos estruturados (LDOs) oriundos da calcinação destes. Porém, um HDL do sistema $\mathrm{Mg} / \mathrm{Al}$, intercalado com o íon $t$-butóxido ( $\mathrm{Mg} / \mathrm{AltBu})$, apresentouse cataliticamente ativo na transesterificação de $\beta$-cetoésteres com alcoóis primários, secundários e terciários. ${ }^{55}$ No que diz respeito ao uso de LDOs, vários trabalhos têm demonstrado que estes materiais possuem elevado potencial para uso como catalisador na produção do biodiesel. ${ }^{56-59}$

HDLs do sistema Mg/Al foram sintetizados pelo método da coprecipitação e os óxidos estruturados (LDOs) deles obtidos foram empregados como catalisadores da metanólise do óleo de soja. $\mathrm{O}$ pH final de precipitação foi de 10 e, após lavagem exaustiva, o sólido foi seco a $85^{\circ} \mathrm{C}$ por $14 \mathrm{~h}$ e calcinado a $500{ }^{\circ} \mathrm{C}$ por $14 \mathrm{~h}$. Foram ainda utilizadas duas amostras de óxido de magnésio, $\mathrm{MgO}$ (I) e $\mathrm{MgO}$ (II), obtidas, respectivamente, da calcinação do $\mathrm{Mg}(\mathrm{OH})_{2}$ e $\left(\mathrm{MgCO}_{3}\right)_{4}$. $\mathrm{Mg}(\mathrm{OH})_{2}$ por $18 \mathrm{~h}$ a $400{ }^{\circ} \mathrm{C}$. Testes catalíticos com estes LDOs, realizados com $10 \%$ de catalisador $(\mathrm{m} / \mathrm{m})$ a $100{ }^{\circ} \mathrm{C}$ por $3 \mathrm{~h}$, forneceram rendimentos próximos a $80 \%$ em ésteres metílicos, enquanto que rendimentos inferiores a $20 \%$ foram obtidos com $\mathrm{MgO}$ (I) e $\mathrm{MgO}$ (II). A $180{ }^{\circ} \mathrm{C}$, o rendimento com LDOs foi próximo de $90 \%$, enquanto que os obtidos com $\mathrm{MgO}(\mathrm{I})$ e $\mathrm{MgO}$ (II) se demonstraram ligeiramente inferiores. ${ }^{56} \mathrm{O}$ desempenho catalítico destes LDOs também foi comparado a uma amostra de $\mathrm{MgO}$ comercial em reações de metanólise dos óleos de soja neutro e contendo $10 \%$ (m/m) de ácido oleico. Os rendimentos obtidos a partir do óleo neutro foram de 92 e $75 \%$, respectivamente, utilizando LDO e $\mathrm{MgO}$ como catalisadores, e de 80,3 e 76,0\% utilizando óleo contendo $10 \%$ de ácido oleico. As reações foram realizadas a $180{ }^{\circ} \mathrm{C}$ por $1 \mathrm{~h}$ com $5 \%$ de catalisador. ${ }^{57}$

HDLs reidratados do sistema $\mathrm{Mg} / \mathrm{Al}$ também foram testados em reações de transesterificação da tributirina. ${ }^{58} \mathrm{HDLs}$ do tipo $\mathrm{Mg}_{4} \mathrm{Al}$ foram calcinados a $500{ }^{\circ} \mathrm{C}$ sob fluxo de $\mathrm{N}_{2}(100 \mathrm{~mL} / \mathrm{min})$ para depois serem reidratados na fase de vapor, sob a premissa de que a atividade catalítica melhoraria com o processo de decomposição/reidratação. ${ }^{59}$ Durante a reidratação, os compostos lamelares foram reconstruídos de forma que as cargas referentes aos ânions carbonato, presentes na estrutura do material antes da calcinação, fossem substituídas por íons hidróxido para formar mais sítios ácidos de Brönsted-Lowry. Este sólido foi utilizado como catalisador na metanólise da tributirina com excesso de metanol, fornecendo rendimentos da ordem $80 \%$ em reações conduzidas a $60{ }^{\circ} \mathrm{C}$ por $400 \mathrm{~min}$, envolvendo $136,5 \mathrm{~g}$ de metanol, 43,0 $\mathrm{g}$ de tributirina e $0,25 \mathrm{~g}$ de catalisador.

Além das reações de transesterificação que visam a produção de monoésteres metílicos, os HDLs também foram ativos na glicerólise do oleato de metila ${ }^{60} \mathrm{HDLs}$ do sistema Li/Al foram ativados em mufla sob fluxo de $\mathrm{N}_{2}$ a $450{ }^{\circ} \mathrm{C}$ por $8 \mathrm{~h}$, com taxa de aquecimento de $2{ }^{\circ} \mathrm{C} /$ min, e os óxidos assim obtidos foram reidratados na temperatura ambiente sob fluxo $\mathrm{N}_{2}$ livre de $\mathrm{CO}_{2}$. Tal estratégia foi utilizada porque HDLs oriundos da reidratação de óxidos estruturados apresentam desempenho catalítico superior ao do material lamelar de origem. ${ }^{61}$ Os experimentos, conduzidos a $200{ }^{\circ} \mathrm{C}$ com $4 \%$ de catalisador a 500 $\mathrm{rpm}$, forneceram conversões de $98 \%$ após $2 \mathrm{~h}$ de reação com KF/ $\mathrm{Al}_{2} \mathrm{O}_{3}, 96 \%$ após $6 \mathrm{~h}$ de reação com $\mathrm{MgO}$ e $98 \%$ após $4 \mathrm{~h}$ de reação com o sistema Li/Al, sendo que, em cada caso, a seletividade para a produção de monoésteres de alquila (oleato de glicerina) foi de 69 ; 73 e $70 \%$, respectivamente. ${ }^{60}$

Liu e colaboradores calcinaram a hidrotalcita $\mathrm{Mg}_{6} \mathrm{Al}_{2}(\mathrm{OH})_{16} \mathrm{CO}_{3} \cdot 4 \mathrm{H}_{2} \mathrm{O}$ em diferentes temperaturas $\left(400-800{ }^{\circ} \mathrm{C}\right)$ por $8 \mathrm{~h}$ sob fluxo de $\mathrm{N}_{2}$, com taxa de aquecimento de $10{ }^{\circ} \mathrm{C} / \mathrm{min}$, para empregá-la como catalisador heterogêneo na metanólise de gordura de frango ${ }^{61}$ Conforme relatado por Xie e colaboradores, o desempenho do catalisador dependeu da temperatura de calcinação. ${ }^{20}$ Rendimentos da ordem de $94 \%$ foram obtidos, sob RM metanol:óleo de $60: 1,10 \%$ de catalisador a $120^{\circ} \mathrm{C}$ por
$6 \mathrm{~h}$, a partir do material calcinado a $500{ }^{\circ} \mathrm{C}$, e a alta atividade catalítica deste material não foi acompanhada por sinais de lixiviação em etapas sequenciais de reuso.

Vários HDLs do sistema $\mathrm{Mg} / \mathrm{Al}$ foram preparados pelo método da coprecipitação. Os produtos obtidos da calcinação destes HDLs foram utilizados como catalisadores na alcoólise do óleo de colza. ${ }^{62} \mathrm{~A}$ atividade do catalisador em reações de metanólise foi correlacionada com a temperatura e o tempo de calcinação e, também, com a razão entre os cátions bivalente e trivalente $(\mathrm{Mg} / \mathrm{Al})$. Os melhores resultados foram obtidos com o catalisador de razão $\mathrm{Mg} / \mathrm{Al}$ igual a 3,0 após calcinação por $12 \mathrm{~h}$ a $500{ }^{\circ} \mathrm{C}$. Na condição de melhor resposta (RM metanol:óleo de 6:1 e 1,5\% de catalisador em relação à massa de óleo a $65^{\circ} \mathrm{C}$ e $300 \mathrm{rpm}$ por $4 \mathrm{~h}$ ), este material forneceu amostras com teor de monoésteres de $90,5 \%$ e os experimentos de reuso demonstraram que o material foi ativo por seis ciclos de reação, com pequena perda de atividade a cada ciclo.

Óxidos nanoestruturados, oriundos da calcinação de HDLs do sistema $\mathrm{Mg} / \mathrm{Al}$ com diferentes quantidades de cátions divalentes e trivalentes, também foram cataliticamente ativos na metanólise do óleo de soja. ${ }^{63}$ Os melhores rendimentos $(67 \%)$ foram obtidos após 9 h de reação sob refluxo, empregando RM metanol:óleo de 15:1 e 7,5\% do catalisador com razão $\mathrm{Mg} / \mathrm{Al}$ de 3,0. Também foi demonstrado que a temperatura de calcinação influencia consideravelmente a atividade catalítica. Quando a temperatura de calcinação passou de 300 para $500{ }^{\circ} \mathrm{C}$, o rendimento da metanólise do óleo de soja aumentou gradualmente até atingir um máximo de $66 \%$, o que foi correlacionado com a força básica do catalisador obtido nestas condições. Entretanto, para temperaturas de calcinação superiores a $500{ }^{\circ} \mathrm{C}$, foram obtidos materiais de menor força básica e, por consequência, de menor resposta catalítica. $\mathrm{O}$ catalisador preparado a $500{ }^{\circ} \mathrm{C}$ apresentou a estrutura do periclásio $(\mathrm{MgO})$ e aquele obtido a temperaturas acima de $500{ }^{\circ} \mathrm{C}$, do espinélio $\left(\mathrm{MgAl}_{2} \mathrm{O}_{4}\right)$, de acordo as caracterizações por XDR. Em temperaturas mais baixas (e.g., $200{ }^{\circ} \mathrm{C}$ ), o $\mathrm{Al}^{3+}$ substituiu grande parte do $\mathrm{Mg}^{2+}$ e a basicidade do $\mathrm{Al}^{3+}$ coordenado com o $\mathrm{O}^{2-}$ foi menor do que a do $\mathrm{Mg}^{2+}$ coordenado com o $\mathrm{O}^{2-}$. Isto explicou a melhor atividade catalítica do sólido de $\mathrm{RM}$ igual a 3 que foi calcinado a $500{ }^{\circ} \mathrm{C}$.

Materiais lamelares da série $\left[\mathrm{Mg}_{1-\mathrm{x}} \mathrm{Al}_{\mathrm{x}}(\mathrm{OH})_{2}\right]^{\mathrm{x}+}\left(\mathrm{CO}_{3}^{2-}\right)_{\mathrm{x} / \mathrm{y}}$, com valores de $\mathrm{x}$ entre 0,25 e 0,55 , foram utilizados na metanólise do tributirato de glicerina após calcinação a $500{ }^{\circ} \mathrm{C}$ por $3 \mathrm{~h}$ sob fluxo de $\mathrm{N}_{2}$ com $95 \%$ de umidade a $100 \mathrm{~mL} / \mathrm{min} .{ }^{64}$ Neste estudo, testes também foram efetuados com $\mathrm{Al}_{2} \mathrm{O}_{3}$ pura e com amostras de hidrotalcita ( $\mathrm{HDL} \mathrm{Mg} / \mathrm{Al}-\mathrm{CO}_{3}$ ) calcinadas com teores crescentes de $\mathrm{Mg}$ e nenhuma atividade catalítica foi observada em ambos os casos. Houve um aumento gradativo na conversão em monoésteres com o aumento do teor de magnésio na estrutura do óxido estruturado (LDOs), cujo ápice foi de 74,8\% quando o catalisador continha $24 \%$ deste elemento. As reações foram realizadas com $0,05 \mathrm{~g}$ de catalisador calcinado, $0,01 \mathrm{~mol}$ de tributirato de glicerina e $0,3036 \mathrm{~mol}$ de metanol a 60 ${ }^{\circ} \mathrm{C}$ por $3 \mathrm{~h}$. Nestas condições, o $\mathrm{MgO}$ puro proporcionou conversão de apenas $11 \%$.

LDOs impregnados com potássio também foram testados como catalisadores heterogêneos para a alcoólise de triacilglicerois ${ }^{65} \mathrm{O}$ material contendo $1,5 \%$ de potássio na matriz foi utilizado como catalisador na metanólise do óleo de palma, tendo sido obtidas amostras com teor de monoésteres de $96,9 \%$ e rendimento de $86,6 \%$ quando a RM utilizada foi de $30: 1$ a $100{ }^{\circ} \mathrm{C}$ por $6 \mathrm{~h}$, usando $7 \%$ de catalisador.

Óxidos estruturados oriundos da calcinação de HDLs dos sistemas $\mathrm{Mg} / \mathrm{Al} \mathrm{e} \mathrm{Zn} / \mathrm{Al}$ foram utilizados, paralelamente ao $\mathrm{MgO}, \mathrm{ZnO}_{\text {e }} \mathrm{Al}_{2} \mathrm{O}_{3}$, como catalisadores em reações de transesterificação metílica do óleo de soja ${ }^{66} \mathrm{~A}$ calcinação foi realizada a $450{ }^{\circ} \mathrm{C}$ por $12 \mathrm{~h}$, com taxa de aquecimento de $1{ }^{\circ} \mathrm{C} / \mathrm{min}$ e os experimentos foram conduzidos nas temperaturas de 70,100 e $130^{\circ} \mathrm{C}$, sendo que, em todos os casos, 
melhores resultados foram obtidos em temperaturas mais elevadas. Na temperatura de $130{ }^{\circ} \mathrm{C}$, os rendimentos obtidos foram de $80 \%$ com o $\mathrm{MgO}, 70 \%$ com óxidos estruturados derivados de HDLs do sistema $\mathrm{Mg} / \mathrm{Al}, 63 \%$ com óxidos derivados de HDLs do sistema $\mathrm{Zn} / \mathrm{Al}, 30 \%$ com $\mathrm{ZnO}$ e $11 \%$ com $\mathrm{Al}_{2} \mathrm{O}_{3}$, quando as reações foram conduzidas por 7 h com RM metanol:óleo de 55:1 e 5\% de catalisador.

Ilgen e colaboradores investigaram o efeito do tamanho de partícula sobre a atividade catalítica de LDOs derivados da calcinação da hidrotalcita $\left(\mathrm{Mg}_{6} \mathrm{Al}_{2}(\mathrm{OH})_{16} \mathrm{CO}_{3} \cdot 4 \mathrm{H}_{2} \mathrm{O}\right) \cdot{ }^{67}$ As reações foram efetuadas utilizando $50 \mathrm{~g}$ de óleo de canola com diferentes volumes de álcool e diferentes quantidades de catalisador, cujo diâmetro médio de partícula era inferior a $125 \mu \mathrm{m}$ ou compreendido nos intervalos de 125-150 e 150-177 $\mu \mathrm{m}$. A melhor condição de reação, que resultou na conversão de $71,9 \%$ dos triacilglicerois em monoésteres metílicos, foi observada após $9 \mathrm{~h}$ sob refluxo a $500 \mathrm{rpm}$, empregando RM metanol:óleo de 6:1 e 3\% do catalisador com partículas de diâmetro médio de 125-150 $\mu \mathrm{m}$. Neste estudo, também foi observado que o uso de $n$-hexano como cossolvente e o aumento da RM para 9, $12 \mathrm{e}$ 16:1 resultaram na queda do rendimento da reação, e que o metanol apresentou melhor desempenho na alcoólise do óleo de canola do que o etanol.

Os LDOs derivados da calcinação da hidrotalcita foram testados como catalisadores para a metanólise do óleo de algodão. Foram obtidas amostras com teor de monoésteres de $95 \%$ quando a reação foi realizada a $180^{\circ} \mathrm{C}$ com $\mathrm{RM}$ metanol:óleo de $6: 1$ e $1 \%$ de catalisador e pressão de 21,7 atm. ${ }^{68}$

Alburquerque e colaboradores empregaram LDOs oriundos da calcinação de HDLs do sistema Mg/Al e misturas de óxidos do sistema $(\mathrm{Mg} / \mathrm{Ca})$ na metanólise do butirato de etila a $60^{\circ} \mathrm{C}$ sob pressão normal. ${ }^{69} \mathrm{O}$ melhor rendimento foi de $45 \%$ quando a razão $\mathrm{Mg} / \mathrm{Ca}$ foi de 3,8 , não tendo sido observada qualquer lixiviação do catalisador durante os experimentos de alcoólise. Este catalisador também foi utilizado na metanólise do óleo de girassol, tendo sido obtido rendimento de 92,4\% com RM metanol:óleo de $12: 1$ a $60^{\circ} \mathrm{C}$, empregando $2,5 \%$ do sólido em relação à massa de material graxo. $\mathrm{O}$ catalisador com razão $\mathrm{Mg} / \mathrm{Al}$ (derivado do HDL) de 5,8 forneceu rendimentos da ordem de $66,3 \%$ sob as mesmas condições experimentais.

HDLs do sistema $\mathrm{Mg} / \mathrm{Al}, \mathrm{Mg} / \mathrm{Fe}$ e $\mathrm{Li} / \mathrm{Al}$ foram utilizados como catalisadores na metanólise do óleo de soja, após calcinação a 450 ${ }^{\circ} \mathrm{C}$ por 2 h. ${ }^{70} \mathrm{O}$ melhor resultado foi obtido com os LDOs oriundos da calcinação do $\mathrm{HDL}\left[\mathrm{LiAl}_{2}(\mathrm{OH})_{6}\right]\left(\mathrm{CO}_{3}\right)_{0,5} \cdot \mathrm{nH}_{2} \mathrm{O}$, cujo rendimento em monoésteres foi de $83,1 \%$ empregando $1 \%$ de catalisador, RM metanol:óleo de 15:1 e 2 h de reação. Sob as mesmas condições, os LDOs oriundos do HDL do sistema $\mathrm{Mg} / \mathrm{Al}$ forneceram rendimentos da ordem de $13,6 \%$. Testes também foram realizados para verificar a atividade destes catalisadores em reações do tributirato de glicerila com metanol. As reações foram conduzidas a $65^{\circ} \mathrm{C}$ sob refluxo e agitação por $3 \mathrm{~h}$, com $20 \mathrm{mmol}$ de tributirato de glicerila, $600 \mathrm{mmol}$ de metanol e $0,1 \mathrm{~g}$ de catalisador. Todos os LDOs do sistema Li/Al apresentaram rendimentos superiores a $98 \%$, enquanto que o melhor rendimento para LDOs oriundos do sistema $\mathrm{Mg} / \mathrm{Al}$ foi de $32,0 \%$ e, nos casos de $\mathrm{Mg} / \mathrm{Fe}$ e $\mathrm{MgO}$, de 23,9 e 37,1\%, respectivamente. Por outro lado, o desempenho catalítico dos LDOs teve relação com a temperatura de calcinação do HDL, sendo que os melhores resultados foram obtidos quando o material lamelar foi calcinado em temperaturas de 450 e $500{ }^{\circ} \mathrm{C}$.

Polioximetalatos foram sintetizados pelo método da coprecipitação, a partir de HDLs do sistema Mg/Al dopados com íons de metais de transição, e foram utilizados como catalisadores em reações de transesterificação metílica da triacetina. ${ }^{71}$ As reações foram realizadas por 0,5 a 2 h com RM metanol:triacetina de 6:1 e $1 \%$ de catalisador a $80{ }^{\circ} \mathrm{C}$. Os experimentos foram realizados por $100 \mathrm{~min}$ com LDOs não dopados, LDOs dopados com 5 e $10 \%$ de $\mathrm{Ga}^{3+}$ e LDOs dopados com 5 e $10 \%$ de $\mathrm{Fe}^{3+}$. LDOs não dopados forneceram rendimentos da ordem de $20 \%$, enquanto que LDOs dopados com 5 e $10 \%$ de $\mathrm{Ga}^{3+}$ atingiram rendimentos da ordem de 60 e $90 \%$, respectivamente. LDOs contendo 5 e $10 \%$ de $\mathrm{Fe}^{3+}$ conduziram a rendimentos praticamente quantitativos.

HDLs contendo os metais $\mathrm{Mg}_{2} \mathrm{AlCo}$, na razão $\mathrm{Mg} / \mathrm{Al}$ indicada, foram utilizados na metanólise do óleo de canola. Rendimentos de $95 \pm 5 \%$ em monoésteres metílicos foram obtidos em sete ciclos consecutivos de reação, realizados sob RM de 16:1, $2 \%$ de catalisador (LDOs) a $200{ }^{\circ} \mathrm{C}, 25$ atm por 180 min. ${ }^{72}$

\section{HIDROXISSAIS LAMELARES E CARBOXILATOS LAMELARES}

Se o cátion trivalente de um HDL for gradativamente substituído pelo divalente, em um caso limite, apenas o cátion divalente vai estar presente e a estrutura resultante passa a ser classificada como um hidroxissal lamelar (HSL). Estes materiais correspondem a estruturas um pouco mais complexas do que a da brucita, porque alguns íons hidróxido dos vértices dos octaedros são substituídos por moléculas de água ou outros ânions. Como as lamelas assim descritas possuem densidade de carga positiva, ânions são intercalados nos espaços interlamelares para promover o equilíbrio elétrico. ${ }^{73}$

A estrutura dos HSLs pode ser classificada em dois tipos, que podem ser representados pelo hidroxinitrato de zinco, $\mathrm{Zn}_{5}(\mathrm{OH})_{8}\left(\mathrm{NO}_{3}\right)_{2} \cdot 2 \mathrm{H}_{2} \mathrm{O}$, e pelo hidroxinitrato de cobre, $\mathrm{Cu}_{2}(\mathrm{OH})_{3} \mathrm{NO}_{3}$. No hidroxinitrato de zinco (HNZ), o íon nitrato não coordena com o íon metálico, enquanto que no hidroxinitrato de cobre um quarto das hidroxilas que coordenam com o metal são substituídas pelo ânion intercalado. A fórmula geral de um hidroxissal é $\mathrm{M}^{2+}(\mathrm{OH})_{2-\mathrm{x}}\left(\mathrm{A}^{\mathrm{n}-}\right)$ ${ }_{x / n} \cdot \mathrm{mH}_{2} \mathrm{O}$, sendo $\mathrm{M}=\mathrm{Mg}, \mathrm{Ni}, \mathrm{Zn}, \mathrm{Cu}, \mathrm{Co}$ e $\mathrm{A}=\mathrm{NO}_{3}{ }^{-}, \mathrm{SO}_{4}{ }^{2-} \mathrm{e} \mathrm{Cl}^{-73}$

A atividade catalítica do $\mathrm{HNZ}$ em reações de esterificação foi demonstrada recentemente. ${ }^{74} \mathrm{O} \mathrm{HNZ}$ foi utilizado como catalisador na esterificação metílica e etílica do ácido láurico, fornecendo amostras com 97,4\% de monoésteres metílicos (RM metanol:ácido graxo de 4:1 e $4 \%$ de catalisador a $140^{\circ} \mathrm{C}$ por $2 \mathrm{~h}$ ) e $77,2 \%$ de monoésteres etílicos (RM de $6: 1$ e $2 \%$ de catalisador a $140{ }^{\circ} \mathrm{C}$ por $2 \mathrm{~h}$ ) nas melhores condições de síntese. Após o uso, o catalisador supracitado foi recuperado e novamente caracterizado por XDR e espectroscopia vibracional no infravermelho com transformada de Fourier (FTIR), tendo sido constatado que o mesmo foi transformado in situ em laurato de zinco (ZL), que atuou como o verdadeiro catalisador da reação. O HNZ empregado neste estudo também foi utilizado como catalisador da metanólise do óleo de palma refinado, tendo sido obtidas amostras com teor de monoésteres da ordem de 95\% quando a RM foi de 48:1, a 150 ${ }^{\circ} \mathrm{C}$, com $5 \%$ de catalisador por $2 \mathrm{~h}$. A glicerina bruta recuperada como subproduto no processo apresentou grau de pureza da ordem de $93 \%$.

A descoberta da atividade catalítica dos carboxilatos lamelares, em reações de esterificação e transesterificação, ${ }^{74}$ abriu uma nova frente de pesquisas para o desenvolvimento de catalisadores industriais, principalmente devido à sua inércia química, facilidade de síntese e às possibilidades de reuso e reciclagem após a sua vida útil. Neste sentido, Zieba e colaboradores propuseram o emprego de $\mathrm{Zn}_{5}(\mathrm{OH})_{8}\left(\mathrm{NO}_{3}\right)_{2} \cdot 2 \mathrm{H}_{2} \mathrm{O}$ como catalisador heterogêneo para a metanólise do óleo de mamona. ${ }^{75}$ Estas reações foram conduzidas com 5\% de catalisador e RM de 29:1, sendo obtidas amostras com conversões em monoésteres superiores a $70 \%$ após $3 \mathrm{~h}$ a $50{ }^{\circ} \mathrm{C}$. Os autores observaram que o $\mathrm{Zn}_{5}(\mathrm{OH})_{8}\left(\mathrm{NO}_{3}\right)_{2} \cdot 2 \mathrm{H}_{2} \mathrm{O}$ pode ser reciclado várias vezes e que também apresenta atividade catalítica na metanólise de triacetina e óleo de soja. Observaram também que o composto $\mathrm{Zn}_{5}(\mathrm{OH})_{8}\left(\mathrm{NO}_{3}\right)_{2} \cdot 2 \mathrm{H}_{2} \mathrm{O}$ sofre uma transformação estrutural para $\mathrm{Zn}_{3}(\mathrm{OH})_{4}\left(\mathrm{NO}_{3}\right)_{2}$ ou $\mathrm{ZnO}$, dependendo das condições de temperatura empregadas nos experimentos. 
Recentemente, Jacobson e colaboradores utilizaram estearato de zinco imobilizado em sílica gel como catalisador da metanólise de óleo residual com $15 \%$ de ácidos graxos livres. ${ }^{76}$ Nestes experimentos, foram obtidos rendimentos de $98 \%$ em monoésteres metílicos quando a reação foi conduzida a $200{ }^{\circ} \mathrm{C}$ por $10 \mathrm{~h}$, com RM metanol:óleo de $18: 1$ e $3 \%$ de catalisador. Portanto, a exemplo do comportamento do laurato de zinco, ${ }^{73} \mathrm{o}$ estearato de zinco imobilizado em sílica gel também se mostrou efetivo na catálise simultânea das reações de esterificação e transesterificação.

$\mathrm{O}$ mesmo grupo de pesquisa que utilizou o HNZ, em reações de esterificação e transesterificação, também realizou um estudo comparativo da esterificação metílica do ácido láurico, utilizando três catalisadores distintos. ${ }^{77} \mathrm{O}$ primeiro, obtido a partir da calcinação do $\mathrm{HNZ}$ a $450{ }^{\circ} \mathrm{C}$ por $2 \mathrm{~h}$, teve sua composição química centrada em $\mathrm{ZnO}$. O segundo correspondeu a uma mistura de óxidos estruturados (LDOs) obtidos através da calcinação do $\mathrm{HDL} \mathrm{Zn}_{2} \mathrm{Al}^{-\mathrm{CO}_{3}}$ a $450^{\circ} \mathrm{C}$ por $2 \mathrm{~h}$. Por fim, o terceiro foi obtido a partir da calcinação, a 450 ${ }^{\circ} \mathrm{C}$ por $2 \mathrm{~h}$, de uma mistura dos óxidos comerciais $\mathrm{ZnO}$ e $\mathrm{Al}_{2} \mathrm{O}_{3}$ na mesma proporção molar presente nos LDOs supracitados. Os LDOs e a mistura de óxidos comerciais $\left(\mathrm{ZnO} / \mathrm{Al}_{2} \mathrm{O}_{3}\right)$ forneceram taxas de conversão superiores a $98 \%$ em monoésteres graxos, utilizando RM metanol:ácido graxo de $6: 1$ e $2 \%$ de catalisador a $140{ }^{\circ} \mathrm{C}$. Já a conversão obtida com o $\mathrm{ZnO}$, oriundo da calcinação do $\mathrm{HNZ}$, foi da ordem de $99 \%$ quando a reação foi conduzida com RM metanol:óleo de 10:1 e $6 \%$ de catalisador a $140{ }^{\circ} \mathrm{C}$ por $2 \mathrm{~h}$. Neste estudo, os catalisadores empregados foram caracterizados por XRD e FTIR antes e após o uso na esterificação metílica do ácido láurico e em todos os casos, sem exceção, houve a transformação dos mesmos em carboxilatos de zinco, a exemplo do que foi constatado anteriormente para o HNZ. ${ }^{74}$ Além disso, experimentos realizados com vários HDLs do sistema $\mathrm{Zn} / \mathrm{Al}$, intercalados com íons nitrato, cloreto e carbonato, demonstraram que estes também têm a sua estrutura química transformada em carboxilato de zinco após o uso como catalisadores na metanólise de ácidos graxos. Desta forma, pode-se dizer que a caracterização dos catalisadores antes e após o uso é de fundamental importância para se assegurar qual a estrutura química que, de fato, é responsável pelo efeito catalítico observado.

\section{CONSIDERAÇÕES FINAIS}

Neste trabalho, demonstrou-se que várias classes de compostos químicos têm potencial como catalisadores para produção do biodiesel em meio heterogêneo. A forma de atuação destes catalisadores depende, naturalmente, da natureza dos sítios catalíticos de Lewis ou de Brönsted-Lowry presentes nestes sólidos. Em adição a isto, é preciso considerar os requisitos que os sítios ácidos de Lewis ou de Brönsted-Lowry devem atender para o bom desempenho do catalisador no processo de produção de monoésteres graxos.

A acidez de Lewis está comumente associada aos sistemas não próticos resultantes da interação com metais, particularmente os de transição, através da capacidade de seus orbitais $d$ incompletos em receber elétrons. ${ }^{78}$ Neste caso, é desejável, por exemplo, que os sítios de Lewis tenham a capacidade de interagir com a carbonila de triacilglicerois e/ou ácidos graxos de modo a potencializar a ação de um nucleófilo (ataque nucleofílico) sobre o carbono da carbonila e, depois de realizado o ciclo catalítico, que a acidez do sítio de Lewis não seja forte o suficiente para dificultar a dessorção das moléculas graxas da superfície. Já no caso dos sítios ácidos de Brönsted-Lowry, o ato de ceder prótons é muitas vezes é acompanhado por fenômenos de lixiação da espécie catalítica. Neste contexto, o aspecto heterogêneo do catalisador é discutível, pois, mesmo que possa ser recuperado e reutilizado várias vezes, a reação catalisada por ácidos de BrönstedLowry é realizada em meio homogêneo.
Além disso, vários outros requisitos são necessários para que materiais sólidos apresentem potencial para uso como catalisadores heterogêneos. Entre estes, pode-se destacar: alta área superficial por unidade de volume; alta seletividade para síntese das moléculas de interesse; possibilidade de várias reutilizações antes da desativação; possibilidade de regeneração do catalisador após desativação; reprodutibilidade dos procedimentos de síntese do catalisador; alta estabilidade térmica; alta resistência mecânica e, alta resistência ao desgaste por fricção. ${ }^{79}$

Em adição às propriedades mencionadas acima, há casos em que ocorre uma mudança radical na estrutura química do catalisador e a nova estrutura formada pode atuar como a verdadeira espécie catalítica, como demonstrado, por exemplo, na transformação in situ do hidroxinitrato de zinco em carboxilato de zinco durante a esterificação metílica do ácido láurico. ${ }^{74}$ Uma série de experimentos complementares, realizados pelo mesmo grupo de pesquisa, mostraram que vários HDLs e óxidos inorgânicos também sofrem mudanças em sua estrutura química ao serem utilizados como catalisadores em reações de esterificação. ${ }^{77}$

Através dos exemplos fornecidos nesta revisão, fica demonstrado que os catalisadores heterogêneos possuem grande potencial para substituir os sistemas homogêneos atualmente empregados na indústria do biodiesel, e que tal substituição oferece vantagens, que propiciam um aumento considerável nas perspectivas de sustentabilidade sócio-ambiental de todo o processo de produção.

\section{AGRADECIMENTOS}

À CAPES, ao CNPq, à FINEP e à Fundação Araucária pelo apoio financeiro.

\section{REFERÊNCIAS}

1. http://www.un.org/english/, acessada em Abril 2010.

2. Zhang, Y.; Dubé, M. A.; McLean, D. D.; Bioresour. Technol. 2003, 89, 1 .

3. Peterson, C. L.; Hustrulid, T.; Biomass and Bioenergy 1998, 14, 91.

4. Schuchardt, U.; Sercheli, R.; Vargas, R. M.; J. Braz. Chem. Soc. 1998, 9, 199.

5. Canacki, M.; Gerpen, J. V.; Trans. Am. Soc. Agric. Eng. 1999, 42, 1203.

6. Silva, F. R.; Dissertação de Mestrado, Universidade Federal do Paraná, Brasil, 2009.

7. Di Serio, M.; Tesser, R.; Pengmei, L.; Santacesaria, E.; Energy Fuels 2008, 22, 207

8. Yan, S.; Salley, S. O.; Simon Ng, K. Y.; Appl. Catal., A 2009, 353, 203.

9. Carvalho, T. E. M.; Fungaro, D. A.; Izidoro, J. C.; Quim. Nova 2010, 33, 358.

10. Caovilla, A.; Rigo, R. T.; Penha, F. G.; Pergher, S. B. C.; Quim. Nova 2009, 32, 1818 .

11. Rigo, R. T.; Pergher S. B. C.; Quim. Nova 2009, 32, 21.

12. Cundy, C. S.; Cox, P. A.; Chem. Rev. 2003, 103, 663.

13. Luna, F.; Schuchardt, U.; Quim. Nova 2001, $24,885$.

14. Karmee, S. K.; Chadha, A.; Bioresour. Technol. 2005, 96, 1425.

15. Shu, Q.; Yang, B.; Yuan, H.; Qing, S.; Zhu, G.; Catal. Commun. 2007, $8,2159$.

16. http://www.iza-structure.org/databases/, acessada em Abril 2010.

17. Jitputti, J.; Kitiyanan, B.; Rangsunvigit, P.; Bunyakiat, K.; Attanatho, L.; Jenvanitpanjakul, P.; Chem. Eng. J. (Amsterdam, Neth.) 2006, 116, 61.

18. Suppes, G. J.; Dasari, M. A.; Doskocil, E. J.; Appl. Catal., A 2004, 257, 213.

19. Ramos, M. J.; Casas, A.; Rodríguez, L.; Romero, R.; Pérez, A.; Appl. Catal., A 2008, 346, 79.

20. Xie, W.; Peng, H.; Chen, L.; Appl. Catal., A 2006, 300, 67. 
21. Alonso, D. M.; Mariscal, R.; Moreno-Tost, R.; Poves, M. D. Z.; Granados, M. L.; Catal. Commun. 2007, 8, 2080.

22. Liu, X.; Piao, X.; Wang, Y.; Zhu, S.; He, H.; Fuel 2008, 87, 1076.

23. Liu, X.; He, H.; Wang, Y.; Zhu, S.; Piao, X.; Fuel 2008, 87, 216.

24. Nakatani, N.; Takamori, H.; Takeda, K.; Sakugawa, H.; Bioresour. Technol. 2009, 100, 1510.

25. Kouzu, M.; Kasuno, T.; Tajika, M.; Sugimoto, Y.; Yamanaka, S.; Hidaka, J.; Fuel 2008, 87, 2798.

26. Albuquerque, M. C. G.; Jiménez-Urbistondo, I.; Santamaría-González, J.; Mérida-Robles, J. M.; Moreno-Tost, R.; Rodríguez-Castellón. E.; Jiménez-López, A.; Azevedo, D. C. S.; Cavalcante Jr., C. L.; MairelesTorres, P.; Appl. Catal., A 2008, 334, 35.

27. Kawashima, A.; Matsubara, K.; Honda, K.; Bioresour. Technol. 2007, 99, 3439.

28. Alonso, D. M.; Mariscal, R.; Granados, M. L.; Maireles-Torres, P.; Catal. Today 2009, 143, 167.

29. Reddy, C. R. V.; Oshel, R.; Verkade, J. G.; Energy Fuels 2006, 20, 1310.

30. Macedo, C. C. S.; Abreu, F. R.; Tavares, A. P.; Alves, M. B.; Zara, L. F.; Rubima, J. C.; Suarez, P. A. Z.; J. Braz. Chem. Soc. 2006, 17, 1291.

31. Sunita, G.; Devassy, B. M.; Vinu, A.; Sawant, D. P.; Balasubramanian, V. V.; Halligudi, S. B.; Catal. Commun. 2008, 9, 696.

32. Garcia, C. M.; Teixeira, S.; Marciniuk, L. L.; Schuchardt, U.; Bioresour. Technol. 2008, 99, 6608.

33. Yan, S.; Salley, S. O.; Simon Ng, K. Y.; Appl. Catal., A 2009, 353, 203.

34. Nakagaki, S.; Bail, A.; Santos, V. C.; Souza, V. H. R.; Vrubel, H.; Nunes, F. N.; Ramos, L. P.; Appl. Catal., A 2008, 351, 267.

35. Tanabe, K.; Okazaki, S.; Appl. Catal., A 1995, 191, 218.

36. Aranda, D. A. G.; Gonçalves, J. A.; Peres, J. S.; Ramos, A. L. D.; Melo, C. A. R.; Antunes, O. A. C.; Furtado, N. C.; Taft, C. A.; J. Phys. Org. Chem. 2009, 22, 709.

37. Sreeprasanth, P. S.; Srivastava, R.; Srinivas, D.; Ratnasamy, P.; Appl. Catal., A 2006, 314, 148.

38. Silveira Neto, B. A.; Alves, M. B.; Lapis, A. A. M.; Nachtigall, F. M.; Eberlin, M. N.; Dupont, J.; Suarez, P. A. Z.; J. Catal. 2007, 249, 154.

39. Liang, X.; Gong, G.; Wu, H.; Yang, J.; Fuel 2009, 88, 613.

40. Zhang, L; Xian, M.; He, Y.; Li, L.; Yang, J.; Yu, S.; Xu, X.; Bioresour. Technol. 2009, 100, 4368.

41. Sharma, Y. C.; Singh, B.; Renewable and Sustainable Energy Reviews 2009, 13, 1646.

42. Ni, J.; Meunier, F. C.; Appl. Catal., A. 2007, 333, 122.

43. Vicente, G.; Coteron, A.; Martinez, M.; Aracil, J.; Industrial Crops and Products 1998, 8, 29.

44. Rezende, S. M.; Coutinho, F. M. B.; Soares, B. G.; Reis, S. C. M.; Reid, M. G.; Lachter, E. R.; Nascimento, R. S. V.; Polímeros Ciência e Tecnologia 2005, 15, 186.

45. Rezende, S. M.; Reis, M. C.; Reid, M. G.; Jr, P. L. S.; Coutinho, F. M. B.; Gil, R. A. S. S.; Lachter, E. R.; Appl. Catal., A 2008, 349, 198.

46. Guerreiro, L.; Castanheiro, J. E.; Fonseca, I. M.; Martin-Aranda, R. M.; Ramos, A. M.; Vital, J.; Catal. Today 2006, 118, 166.

47. Marchetti, J. M.; Miguel, V. U.; Errazu, A. F.; Fuel 2007, 86, 906.

48. Soldi, R. A.; Oliveira, A. R. S.; Ramos, L. P.; César-Oliveira, M. A. F.; Appl. Catal., A 2009, 361, 42.

49. Lou, W. Y.; Zong, M. H.; Duan, Z. Q.; Bioresour. Technol. 2008, 99, 8758 .
50. Melero, J. A.; Bautista, L. F.; Morales, G.; Iglesias, J.; Briones, D.; Energy Fuels 2009, 23, 539.

51. Schuchardt, U.; Vargas, R. M.; Gelbard, G.; J. Mol. Catal. A: Chem. 1995, 99, 65 .

52. Faria, E. A.; Ramalho, H. F.; Marques, J. S.; Suares, P. A. Z.; Prado, A. G. S.; Appl. Catal., A 2008, 338, 72.

53. Crepaldi, E. L.; Valim, J. B.; Quim. Nova 1998, 21, 300.

54. Bravo-Suárez, J. J.; Páez-Mozo, E.; Oyama, S. T.; Quim. Nova 2004, 27, 601.

55. Choudary, B. M.; Kantam, M. L.; Reddy, Ch. V.; Aranganathan, S.; Santhi, P. L.; Figueras, F.; J. Mol. Catal. A: Chem. 2000, 159, 411.

56. Serio, M. D.; Ledda, M.; Cozzolino, M.; Minutillo, G.; Tesser, R.; Santacesaria E.; Ind. Eng. Chem. Res. 2006, 45, 3009.

57. Serio, M. D.; Cozzolino, M.; Tesser, R.; Patrono, P.; Pinzari, F.; Bonelli, B.; Santacesaria, E.; Appl. Catal., A 2007, 320, 1.

58. Xi, Y.; Davis, R. J.; J. Catal. 2008, 254, 190.

59. Rao, K. K.; Gravelle, M.; Valente, J. S.; Fiqueras, F.; J. Catal. 1998, 173, 115.

60. Corma, A.; Hamid, S. B. A.; Iborra, S.; Velty, A.; J. Catal. 2005, 234, 340.

61. Liu, Y.; Lotero, E.; Goodwin Jr., J. G.; Mo, X.; Appl. Catal., A 2007, $331,138$.

62. Zeng, H.; Feng, Z.; Deng, X.; Li, Y.; Fuel 2008, 87, 3071.

63. Xie, W.; Peng, H.; Chen, L.; J. Mol. Catal. A: Chem. 2006, 246, 24.

64. Cantrell, D. G.; Gillie, L. J.; Lee, A. D.; Wilson, K.; Appl. Catal., A 2005, 287, 183 .

65. Trakarnpruk, W.; Porntangjitlikit, S.; Renewable Energy 2008, 33, 1558.

66. Antunes, W. M.; Veloso, C. O.; Henriques, C. A.; Catal. Today 2008, 133,548

67. Ilgen, O.; Dinçer, I.; Yildiz, M.; Alptekin, E.; Boz, N.; Çanakçi, M.; Akin, A. N.; Turk. J. Chem. 2007, 31, 509.

68. Barakos, N.; Pasias, S.; Papayannakos, N.; Bioresour. Technol. 2008, 99, 5037.

69. Albuquerque, M. C. G.; Santamaría-González, J.; Mérida-Robles, J. M.; Moreno-Tost, R.; Rodríguez-Castellón, E.; Jiménez-López, A.; Azevedo, D. C. S.; Cavalcante Jr., C. L.; Maireles-Torres, P.; Appl. Catal., A 2008, 347, 162.

70. Shumaker, J. L.; Crofcheck, C.; Tackett, S. A.; Santillan-Jimenez, E.; Morgan, T.; Ji, Y.; Crocker, M. ; Toops, T.; Appl. Catal., B 2008, 82, 120.

71. Macala, G. S.; Robertson, A. W.; Johnson, C. L.; Day, Z. B.; Lewis, R. S.; White, M. G.; Iretskii, A. V.; Ford, P. C.; Catal. Lett. 2008, 122, 205.

72. Li, E.; Xu, Z. P.; Rudolph, V.; Appl. Catal., B 2009, 88, 42.

73. Arigaza, G. G. C.; Satyanarayana, K. G.; Wypych, F.; Solid State Ionics 2007, 178, 1143 .

74. Cordeiro, C. S.; Arizaga, G. G. C.; Ramos, L. P.; Wypych, F.; Catal. Commun. 2008, 9, 2140.

75. Zieba, A.; Pacula, A.; Drelinkiewicz, A.; Energy Fuel 2010, 24, 634.

76. Jacobson, K.; Gopinath, R.; Meher, L. C.; Dalai, A. K.; Appl. Catal., B 2008, 85,86 .

77. Cordeiro, C. S.; Tese de Doutorado, Universidade Federal do Paraná, Brasil, 2008.

78. Moreno, E. L.; Rajagopal, K.; Quim. Nova 2009, 32, 538.

79. Chorkendorff, I.; Niemantsverdriet, J. W.; Concepts of Modern Catalysis and Kinetics, Wiley-VCH Verlag GmbH \& Co. KGaA: Weinheim, 2003. 